\title{
ECUADOR: LA DEMOCRACIA DESPUÉS DE NUEVE AÑos DE LA "Revolución CiUdadana" DE RAFAEl CORREA*
}

\author{
Ecuador: Democracy After Nine Years of Rafael Correa's \\ "Citizen's Revolution"
}

SOFÍA VERA ROJAS

University of Pittsburgh

SANTIAGO LLANOS-ESCOBAR

Facultad Latinoamericana de Ciencias Sociales, FLACSO Ecuador

\section{RESUMEN}

En el 2015 confluyeron una serie de problemas que han generado incertidumbre en torno al futuro de la "Revolución Ciudadana" del presidente ecuatoriano Rafael Correa. El desplome de los precios del petróleo golpeó fuertemente a la economía ecuatoriana, centrada en la exportación de recursos naturales y dependiente del gasto público. La insatisfacción ciudadana se hizo sentir a través de masivas jornadas de protesta en contra de las reformas legislativas y las enmiendas constitucionales del oficialismo. Y el inesperado declive en la popularidad de Correa, junto a su decisión de abstenerse de buscar la reelección en el 2017, configuran un escenario difícil para el correísmo. La suerte del oficialismo en los próximos comicios dependerá de cómo se resuelvan estas tensiones en el 2016.

Palabras clave: Ecuador, Rafael Correa, "Revolución Ciudadana", democracia.

\begin{abstract}
Several problems converged in 2015 to generate uncertainty about the future of Correa's "Citizen's Revolution". The drop in oil prices severely hit the Ecuadorian economy based on the exportation of raw materials and dependent on public spending. Public dissatisfaction was channeled through massive protests against the legislative reforms proposed by the governing forces. Moreover, Correa's sudden decline in the popularity, in addition to his decision to abstain from seeking reelection in 2017, have created a difficult scenario for correismo. The fortune of the governing forces in the forthcoming elections will depend on how they resolve these tensions during 2016.
\end{abstract}

Key words: Ecuador, Rafael Correa, "Citizen Revolución", democracia. 


\section{INTRODUCCIÓN}

El 2015 fue un año clave para el futuro de la "Revolución Ciudadana" iniciada en el 2007, a partir de la elección de Rafael Correa como Presidente de la República. El proyecto político de Alianza País enfrenta uno de los momentos más críticos en sus nueve años, marcado principalmente por la crisis económica y el descontento social.

Ante la caída de los precios del petróleo, el gobierno incurrió en mayor endeudamiento público y recortó la inversión pública, lo que ha dificultado el estilo de gobierno manejado durante los últimos años. Las protestas en contra de proyectos de ley impulsados por el oficialismo, como las reformas a los impuestos a la herencia y plusvalía y las enmiendas constitucionales, fueron masivas. El gobierno salió debilitado de las elecciones locales del 2014, pues fue derrotado en municipalidades importantes, principalmente en Quito, Guayaquil y Cuenca. Además, Correa acabó el año con una popularidad reducida, registrándose los índices de aprobación más bajos de toda su gestión. Menospreciando la creciente insatisfacción ciudadana, la Asamblea aprobó las enmiendas constitucionales que abren la posibilidad de reelección indefinida para Correa, aunque la postergación de su entrada en vigencia signifique que este no podrá presentarse en los comicios del 2017. Este panorama social y político, junto con la crisis económica que ya se siente en el país, configuran un escenario de incertidumbre para la continuación del proyecto político de Correa.

Se avizoran momentos difíciles para el correísmo, dado el contexto regional en que los otros gobiernos de izquierda en América Latina están llegando a su fin, y considerando el golpe económico que los bajos precios del petróleo suponen para una economía centrada en la exportación de recursos naturales y dependiente del gasto público. El 2016 será un año decisivo en el que se definirán el legado de la "Revolución Ciudadana" de cara a las elecciones del 2017 y las posibilidades electorales de un gobierno del oficialismo $\sin$ Correa.

\section{TEMAS DE COYUNTURA}

\section{Coyuntura social}

En el 2015 la coyuntura social estuvo marcada por la intensa movilización social. Como se ve en la Figura 1, esta aumentó considerablemente en comparación con años previos. Aunque extendidas a lo largo del año, las jornadas de protestas más importantes se dieron, primero, en torno a los proyectos de ley de herencia y plusvalía, que proponían un paquete de modificaciones al régimen tributario de los impuestos a la herencia y plusvalía respectivamente. ${ }^{1}$ Luego, en el mes de agosto, a partir del paro nacional convocado por organizaciones indígenas y trabajadores. Y finalmente, en oposición al

1 Denominados “Ley Orgánica para la Redistribución de la Riqueza” y “Proyecto de Ley Orgánica Reformatoria al Código Orgánico de Organización Territorial, Autonomía y Descentralización” (proyectos de Ley presentados por el Presidente de la República los días 5 y 8 de junio de 2015 respectivamente). 
Figura 1. Número de protestas en Ecuador (2007-2015)

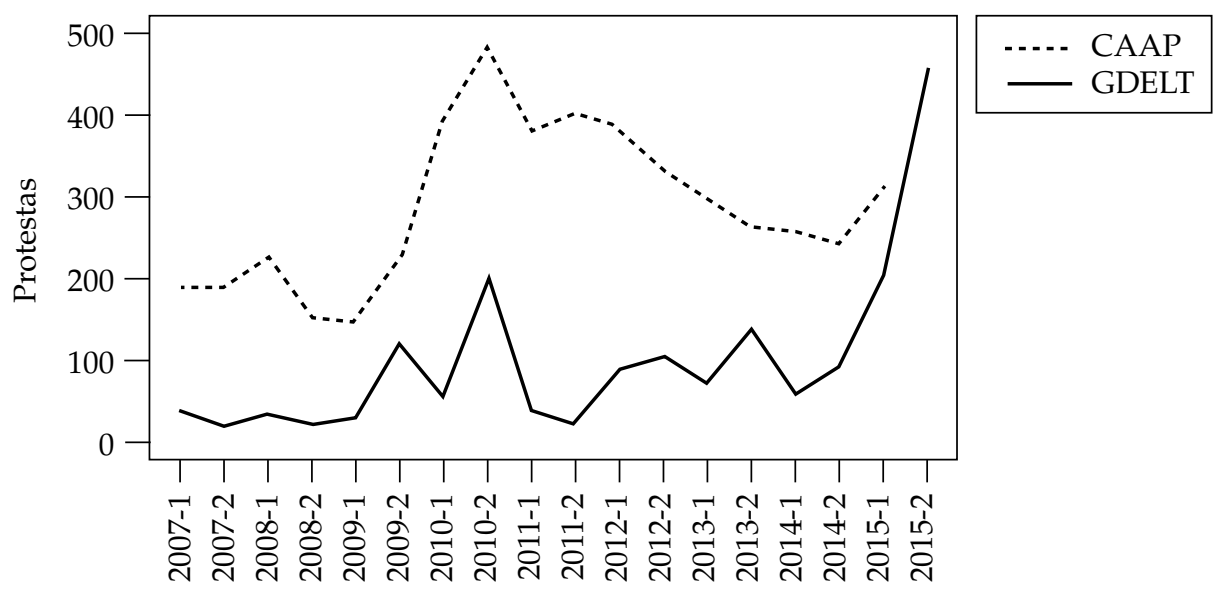

Semestres

Fuente: CAAP y Proyecto GDELT. ${ }^{2}$

paquete de enmiendas constitucionales, que proponía entre otras cosas la reelección indefinida de autoridades en cargos de representación.

Durante el mes de junio, el anuncio, presentación, y posterior discusión de los proyectos de ley de herencia y plusvalía generaron un nutrido debate. Este fue alimentado, de una parte, por la permanente concentración de manifestantes a favor y en contra de las iniciativas legales en varias ciudades, y de otra, por la intensa campaña del oficialismo para evidenciar que los altos márgenes impositivos previstos en dichas leyes únicamente afectaban a las personas de mayores recursos. ${ }^{3}$ Sin embargo, la campaña de comunicación y discusión pública del gobierno no dio los resultados esperados, pues las movilizaciones aumentaron y se agudizaron en todo el territorio ecuatoriano.

La capacidad de movilización de los simpatizantes del gobierno no fue la esperada, siendo superados en número por la oposición en varias ocasiones. El llamado a las bases de Alianza País para su movilización generó, inclusive, la salida temporal del ministro de Relaciones Exteriores, Ricardo Patiño, con el fin de organizar a los partidarios de AP,

2 El proyecto GDELT posee una base de datos de eventos de protesta en el mundo desde 1979, codificados a partir de notas de prensa. Los eventos de protesta incluyen una gran variedad de acciones: demostraciones pacíficas, huelgas, paros, boicots y movilizaciones violentas. Aunque esta base de datos es útil para los propósitos de este artículo, muchos investigadores han notado sus limitaciones (Weller y McCubbins, 2014).

3 El proyecto de Ley Orgánica para la Redistribución de la Riqueza contempló, a manera de un impuesto progresivo, un incremento sustancial de las tarifas de liquidación del impuesto, que incrementaban la máxima carga impositiva para las herencias y cualquier incremento patrimonial a título gratuito hasta un $47,5 \%$ del total de su valor en caso de que los beneficiarios sean los legitimarios del causante o donante-hijos y padres, y hasta el 77,5\% en caso de no ser legitimarios. Por su parte, las modificaciones al régimen de pago del impuesto a la plusvalía incrementaron el valor a pagar al momento de transferir un bien inmueble antiguo. Cabe destacar que ambos regímenes incluyeron excepciones, cuya aplicación aminoraría los valores finales a cancelar. 
en la búsqueda de una respuesta a las manifestaciones organizadas por la oposición y autoconvocadas por la ciudadanía.

En el contexto de un antagonismo exacerbado por el permanente llamado a la confrontación y la defensa de la llamada "Revolución Ciudadana", así como por las convocatorias políticas efectuadas por políticos de la oposición, se suscitó la intervención policial. La policía cercó espacios públicos estratégicos, reprimió a los manifestantes, y desalojó las calles por la noche. Dada la presión social, el proyecto de impuestos a herencias experimentó varias modificaciones, evidenciando un retroceso del gobierno en su afán redistributivo de la riqueza privada. Finalmente, ante la poca efectividad de las medidas, el Presidente decidió retirar ambos proyectos de ley, alegando la necesidad de asegurar un estado de armonía durante la visita del Papa Francisco, efectuada entre el 5 y el 8 de julio de $2015 .{ }^{4}$ No obstante, advirtió que ambos proyectos de ley serían presentados nuevamente.

La última jornada de protestas se efectuó durante los meses de noviembre y diciembre, debido a la cercanía del segundo debate de las enmiendas constitucionales promovidas desde el Ejecutivo. ${ }^{5}$ Las reformas pretendieron la modificación de varios elementos de la Constitución ecuatoriana, principalmente la posibilidad de reelección indefinida de las autoridades de elección popular. El trámite legislativo de las reformas generó reacciones de diversos grupos sociales en contra de su aprobación. Incluso, los tópicos tratados generaron la reacción negativa de personajes afines al gobierno, como el Contralor General del Estado.

En general, las manifestaciones suscitadas durante el año 2015 incluyeron a todos los grupos sociales: trabajadores, indígenas, miembros de la clase media y sectores económicos de alto poder adquisitivo (El Telégrafo, 2015a; 2015b). En particular, las protestas en contra de las leyes de herencia y plusvalía tuvieron un perfil de clase media o alta. Sin embargo, dada la ruptura del gobierno con sectores de izquierda que anteriormente lo apoyaban, el potencial de grupos movilizados en contra de este es alto. La diversidad de posiciones ideológicas de estos grupos pone en evidencia la gravedad de la insatisfacción ciudadana con el gobierno.

La respuesta del gobierno fue la movilización de sus bases y sus partidarios, así como la criminalización de los manifestantes, existiendo detenidos durante las jornadas de protesta que fueron acusados de distintos delitos de forma aparente arbitraria. Algunos casos paradigmáticos son: 21 personas detenidas en el parque "El Arbolito" (El Comercio, 2015a), la detención de la periodista Manuela Picq (El Comercio, 2015b); la detención del transportista de materiales de protesta en Guayaquil (El Comercio, 2015c), entre otros. En el otro lado, hubo también varios miembros de la policía heridos durante las jornadas de protesta. La situación del país, inclusive, generó el pronunciamiento de una relatoría

4 A partir del anuncio de la visita del Papa Francisco al Ecuador, el gobierno nacional emprendió una campaña mediática utilizando la imagen y frases del pontífice, condenando la violencia y promoviendo la redistribución de la riqueza.

5 También se suscitaron importantes manifestaciones de inconformidad ciudadana en agosto a raíz del paro nacional convocado el 13 de agosto de 2015 por organizaciones indígenas y de trabajadores. 
especial de la ONU, llamando a la calma y al diálogo dentro del territorio ecuatoriano (El Comercio, 2015d).

En conclusión, el contexto social se ha visto marcado principalmente por el incremento de la insatisfacción frente al proceder del gobierno de Rafael Correa. Esto se debe principalmente a cambios institucionales y a la situación económica que enfrenta el Ecuador, que implica una disminución de la inversión social y la dificultad de cumplimiento de las obligaciones frente a los servidores públicos y las periferias nacionales. Lo cual a su vez genera tensión y constantes demandas sociales que no pueden ser atendidas de forma directa debido a las limitaciones presupuestarias relacionadas con la disminución del precio de los hidrocarburos.

\section{Coyuntura económica}

La situación del país sufrió una descomposición sustancial frente a las condiciones económicas de años anteriores. A medida que el año 2015 avanzaba, la reducción del precio del petróleo, así como la valorización del dólar en mercados internacionales, generaron complicaciones. La tasa de crecimiento del PIB se registró considerablemente menor en el año $2015(0,4 \%),{ }^{6}$ y los organismos internacionales han proyectado la entrada en recesión para el $2016(-2,0 \%),{ }^{7}$ aunque el gobierno prevé un crecimiento del 1\%. En respuesta al déficit anunciado por el BM -o a la "desaceleración" según el oficialismo, el gobierno recortó 4\% del presupuesto y recurrió a más endeudamiento.

La economía ecuatoriana, relativamente dependiente del petróleo, experimenta un panorama desalentador ante la drástica caída del precio del crudo. Evidenciando la falta de previsión, el gobierno de Correa presupuestó un barril de petróleo a \$ 79 para el 2015, lo cual lo obligó luego a adquirir deuda pública para cubrir la disminución de sus ingresos y financiar el presupuesto previsto. Con el precio internacional del barril entre los \$ 22 y \$ 40 en los últimos meses del 2015, los costos de producción superan los de venta. De esta forma, en el 2015 el Ecuador experimenta un incremento en su porcentaje de deuda con relación al PIB, aunque esta tendencia se venía presentando desde el 2011 (Basabe-Serrano y Martínez, 2014) (ver Figura 3). El principal acreedor del Ecuador continúa siendo China (Gallagher, 2013).

Otra de las medidas para paliar la crisis que se veía venir desde finales del año 2014, fue el establecimiento de salvaguardias a las importaciones, con el fin de evitar la salida de dólares del Ecuador y proteger la producción nacional. Mediante sus resoluciones 11 y 16, el Comité de Comercio Exterior impuso una sobretasa extraordinaria por 15 meses a varios productos importados, entre ellos, alimentos de primera necesidad, ropa, tecnología, etc. ${ }^{8}$ Esto ocasionó la caída de las importaciones, el incremento de los precios

$6 \quad$ El porcentaje de crecimiento corresponde a la proyección efectuada por el Banco Central del Ecuador ( $E l$ Universo, 2015a).

7 En la fecha en que escribimos este artículo, el Banco Mundial proyectaba para el 2016 un crecimiento negativo de $-2,0 \%$ mientras que el FMI $-0,1 \%$.

8 Aunque esta resolución sufrió modificaciones durante su vigencia, eliminando la tasa para varios productos y disminuyendo su cuantía, los términos generales de la medida continúan vigentes. La primera modificación 
Figura 2. Crecimiento económico del Ecuador (2006-2016)

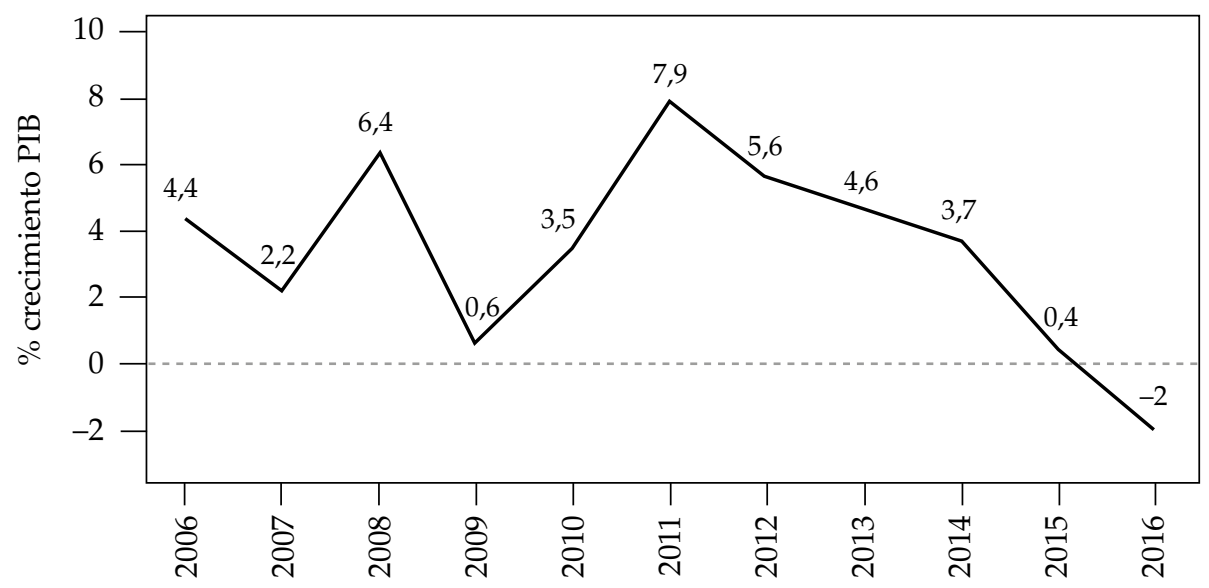

Fuente: Banco Mundial.

Figura 3. Deuda pública en relación al PIB

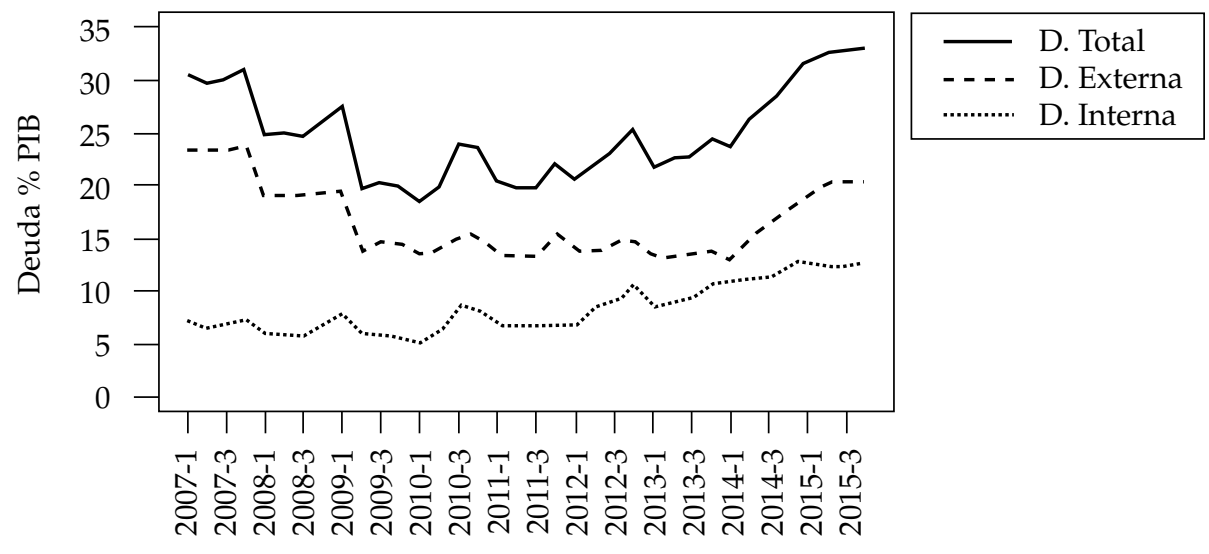

Cuatrimestres

Fuente: Ministerio de Finanzas.

de venta al público, y la disminución de la demanda. Las salvaguardias, junto con la restricción de importaciones suscitadas durante períodos previos, generaron dificultades para los grandes negocios. Algunos sectores, como el automotor y la construcción, han experimentado fuertes ajustes, inclusive, cerrando sus locales y fábricas. ${ }^{9}$

al régimen establecido para el pago de las sobretasas se efectuó mediante la resolución 16-2015. A partir de su vigencia, los rubros para algunas importaciones, como los neumáticos, fueron reducidos. Además, como medida adicional, en el Ecuador se paga un impuesto de salida de capitales equivalente al $5 \%$ del total del monto enviado al exterior.

9 La empresa Maresa, una de las más grandes del sector automotor ecuatoriano, cerró su planta ensambladora por necesidad de reestructuración de su negocio (El Universo, 2015b). 
Además de la contratación de deuda y el establecimiento de salvaguardias, se tomaron otras medidas para enfrentar la crisis, especialmente para cubrir la necesidad de fondos del régimen. Por ejemplo, las preventas de petróleo y la concesión de campos petroleros a compañías extranjeras. Ecuador recurrió a financistas no convencionales, incluyendo una preventa de petróleo a Tailandia y la concesión del campo petrolero Auca a la empresa multinacional Schlumberger. Asimismo, las autoridades gubernamentales han emprendido varias giras internacionales con el fin de buscar recursos en el exterior. Y no se niega la eventual recurrencia a organismos internacionales multilaterales, como el Banco Mundial, el Banco Interamericano de Desarrollo, o el Fondo Monetario Internacional, pese a que el gobierno ha mantenido una retórica encendida en contra de sus políticas.

El riesgo país incrementó de forma sustancial. Durante el mes de diciembre de 2014, dicho indicador, según datos proporcionados por el Banco Central del Ecuador, cerró en 883 puntos. Mientras que al final del mes de diciembre de 2015 se ubicó en 1.266 puntos. ${ }^{10}$ Para el gobierno de Rafael Correa, la disminución de este indicador fue una prioridad, por su necesidad de buenas condiciones de crédito. Aún así, el valor del riesgo país nunca fue el ideal para la contratación de deuda pública, y las condiciones impuestas por los acreedores no han sido las más favorables.

Con el mismo fin, el gobierno ecuatoriano transparentó sus cifras frente a entidades financieras multilaterales y recibió un conjunto de consejos, tendientes a la estabilización de su economía. Incluso hubo varias medidas de ajuste que concuerdan con las recomendaciones del Fondo Monetario Internacional (El Comercio, 2015e; 2015f). Entre estas destacan la supresión parcial de subsidios a los combustibles, ${ }^{11}$ la eliminación del aporte estatal obligatorio al Instituto Ecuatoriano de Seguridad Social, ${ }^{12}$ la eliminación al subsidio de transporte interprovincial, entre otras.

En síntesis, la situación económica del Ecuador fue muy compleja en el año 2015 y se prevé una situación aún más compleja para el 2016. Algunas proyecciones indican que Ecuador sería golpeado más fuertemente que otros países petroleros que sí han podido diversificar su economía, como Canadá, Indonesia, o Malasia, o que tienen reservas monetarias para aplicar políticas contra-cíclicas, como Noruega, Brunei, o los países del golfo pérsico (Dabrowski, 2015). El país continúa siendo moderadamente dependiente del petróleo, el cual representa el 57\% de las exportaciones y alrededor del 16\% del PIB (ver

10 La reducción del riesgo país durante el último trimestre del año se produjo debido al cumplimiento de una serie de obligaciones adquiridas previamente. Por su vencimiento, fueron pagados US\$ 650 millones de dólares en bonos del Estado (El Comercio, 2015g).

11 De forma específica, el decreto ejecutivo 799 modificó el reglamento que regula los precios de los derivados de los hidrocarburos. Las principales reducciones de subsidios a los hidrocarburos se enfocaron en combustible de uso comercial e industrial. Adicionalmente, el gobierno anunció la próxima venta de las gasolineras pertenecientes a la empresa pública EP PETROECUADOR, junto con un incremento sostenido del precio de la gasolina "súper" (alto octanaje).

12 Mediante la aprobación de la Ley Orgánica para la Justicia Laboral y Reconocimiento del Trabajo en el Hogar se eliminó el aporte estatal obligatorio al Régimen de Seguridad Social (equivalente al $40 \%$ del fondo de pensiones). La reforma contempló que existirá un aporte estatal en la medida de las necesidades del Instituto Ecuatoriano de Seguridad Social, IESS (El Universo, 2015c). 
Figura 4. PIB petrolero (2000-2013)

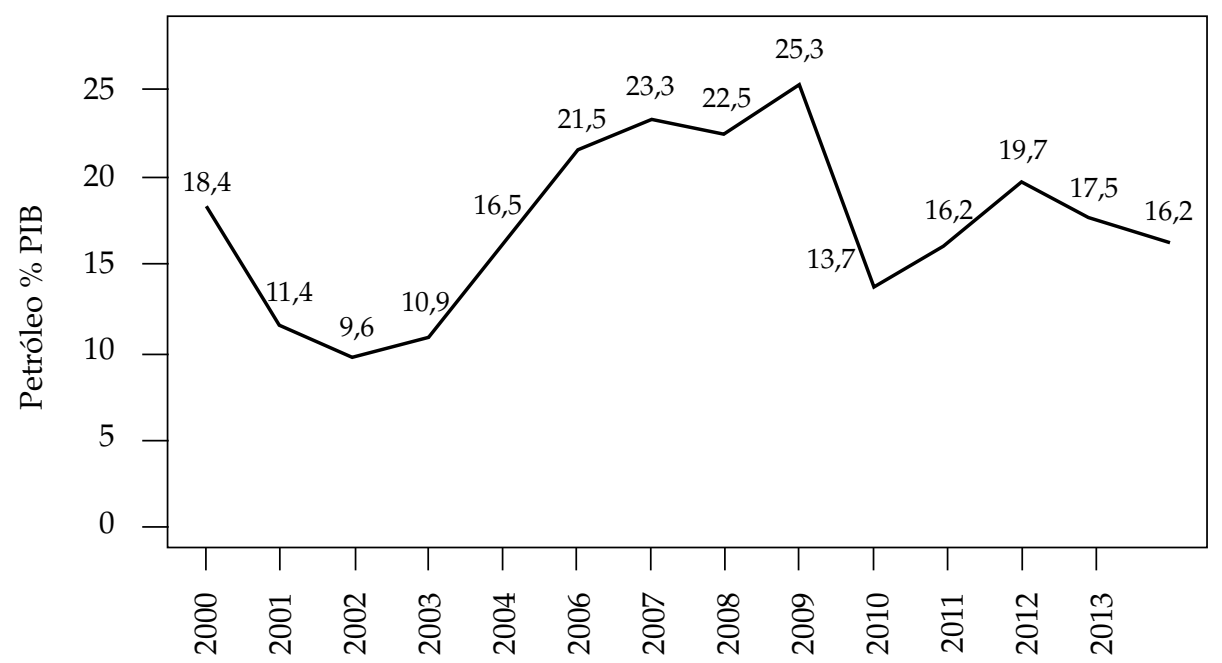

Fuente: Banco Central.

Figuras 4 y 5). A pesar de que la principal fuente de ingresos fiscales es la recaudación tributaria y no el petróleo, los ingresos tributarios también serían alterados por la baja de los precios del petróleo. Sumado a esto, la dolarización de la economía no le permite al gobierno utilizar la desvalorización de la moneda nacional como válvula de escape, así como lo vienen haciendo Colombia y Perú.

No ha existido un verdadero cambio de la matriz productiva, y aún más, los sectores comercial e industrial han soportado una fuerte disminución de sus ingresos, dada la inestabilidad institucional, las altas cargas impositivas y la dificultad para hacer negocios. ${ }^{13}$ La falta de pagos, principalmente de empresas estatales, ha provocado la desgracia de ciertas periferias ubicadas en zonas fronterizas o altamente dependientes de la industria petrolera (El Comercio, 2015h). Además, se han experimentado casos de reestructuración y despidos que, aunque todavía no se ven reflejados en las estadísticas nacionales, dan indicios de la difícil situación que se avecina (El Universo, 2015d).

Por último, la crisis del año 2015 tuvo como actor a un país sin ahorros -a diferencia de la crisis de 2009, que ha gastado sus ingresos en inversión pública, que, aunque contribuye al desarrollo del país, no otorga la liquidez necesaria para el cumplimiento de todas las obligaciones del Estado adquiridas previamente. A pesar de la disminución de la pobreza, que pasó del $37 \%$ en el 2007 al 22\% en el 2014 según estadísticas oficiales, no hay evidencia que se ha generado un cambio económico sustentable, donde sectores diferentes al petrolero se hayan dinamizado y puedan sostener el desarrollo del Ecuador, especialmente en momentos críticos como el actual. Si bien la inversión en 
Figura 5. Exportaciones petroleras por país (2013)

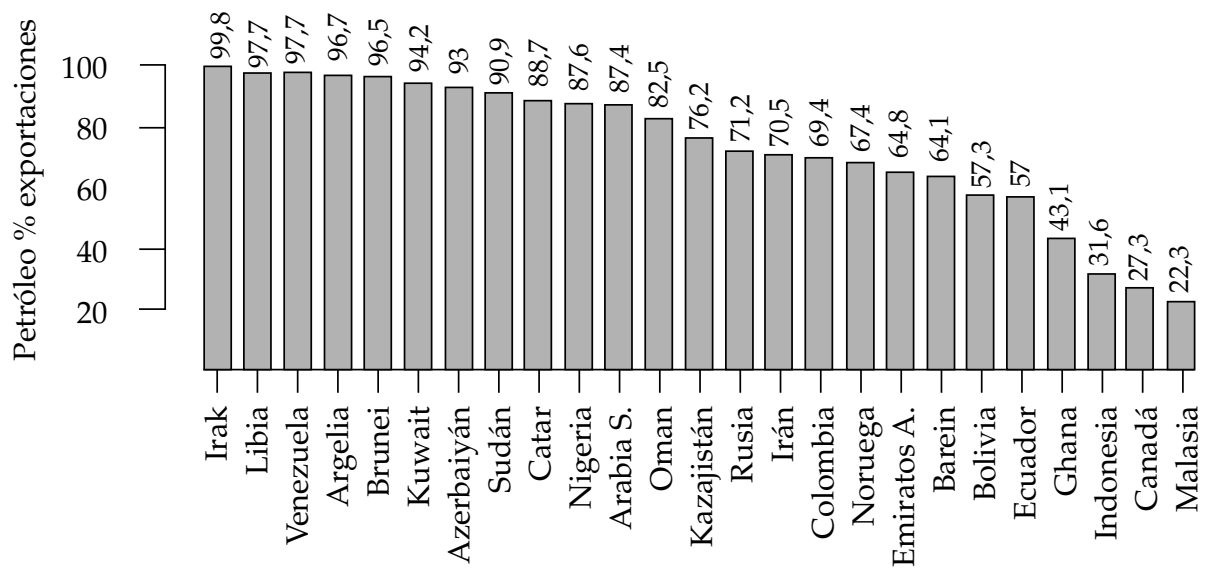

Países petroleros

Fuente: Banco Mundial.

infraestructura, tecnología, y conocimiento fueron una prioridad en los últimos años, la estructura económica del país continúa haciéndolo vulnerable a los cambios externos y existe incertidumbre sobre si el gobierno aprovechó la época de bonanza y sentó las bases económicas para atenuar el golpe de la caída de los precios.

\section{Coyuntura subregional e internacional}

Entre las situaciones de mayor relevancia para el Ecuador, se destacan los procesos políticos de Argentina, Bolivia y Venezuela. En Argentina, después de 12 años de kirchnerismo, los ciudadanos le otorgaron la victoria al candidato de la derecha, Mauricio Macri, quien inició su mandato presidencial con medidas de ajuste y críticas al régimen venezolano. ${ }^{14}$ En Bolivia, Evo Morales perdió el referéndum que le iba a permitir postular a la reelección para un cuarto mandato en el 2019. Finalmente, en Venezuela, las elecciones legislativas del 6 de diciembre marcaron la contundente victoria de la propuesta opositora al chavismo, que obtuvo la mayoría absoluta de la Asamblea Nacional. ${ }^{15}$

Mauricio Macri ganó la presidencia dentro del balotaje suscitado el 22 de noviembre de 2015, tras pasar a segunda ronda electoral junto con el candidato del oficialismo, Daniel Scioli.

15 En total, la oposición venezolana, mediante la presentación de una lista única, obtuvo un total de 112 asientos en el legislativo. Aunque sólo obtuvieron el $58 \%$ de los votos, esto se tradujo a dos tercios del total se escaños legislativos, gracias al sistema electoral. A pesar de la victoria en los comicios, el Tribunal Supremo de Justicia intervino e impidió que tres de los asambleístas electos de la oposición se posesionen en sus cargos, lo que restó fuerza a la mayoría opositora. Desde este reducto, la oposición venezolana ha sostenido una nueva agenda tendiente a la superación económica de Venezuela. Aún así, considerando que el chavismo controla las funciones ejecutiva y judicial, los tres principales poderes del Estado se encuentran en una pugna persistente. 
Los países que constituyeron, junto a Ecuador, el bloque de la "izquierda radical" de América Latina (Castañeda, 2006) estarían atravesando por un debilitamiento que podría configurar un eventual cambio de las tendencias regionales. El electorado latinoamericano parecería indicar que las izquierdas en América Latina están perdiendo el apoyo ciudadano en la región (Navia, 2015). Si las tendencias se mantienen, el "populismo de izquierda" de la "Revolución Ciudadana" (De la Torre, 2013) perdería a sus principales socios ideológicos en la región. Y esto podría impactar el ánimo de los electores ecuatorianos en el 2017 y fortalecer las posiciones de los grupos de derecha en el país.

Las políticas económicas implementadas por el régimen de Rafael Correa, direccionadas a las importaciones y exportaciones, han modificado el contexto de las relaciones internacionales del país. En primer sentido, la imposición de sobretasas a las importaciones dificultó la negociación de acuerdos comerciales, principalmente con la Unión Europea. A pesar de estas medidas, las negociaciones prosperaron, y finalmente contaron con el visto bueno de Colombia y Perú, quienes suscribieron el acuerdo con Europa anteriormente. El oficialismo espera que este acuerdo pueda aumentar las inversiones y las transferencias de tecnología, lo que a largo plazo podría facilitar el cambio de matriz productiva.

Por otra parte, Ecuador emprendió una campaña junto con Venezuela ante los miembros de la Organización de Países Exportadores de Petróleo (OPEP) (El Comercio, 2015i). La intención principal fue disminuir la cuota de exportación de los países que integran la organización, buscando que esto incremente los precios de los hidrocarburos. Sin embargo, la petición de ambas naciones no fue escuchada, y, Arabia Saudita, junto con los miembros más grandes de la OPEP y la mayoría de sus integrantes decidieron mantener los niveles de producción, con el fin de evitar la pérdida de sus cuotas de mercado frente a países no alineados a la organización, principalmente Rusia y Estados Unidos, cuyas producciones se han incrementado de forma sostenida durante los últimos años.

La tensión relativa con los Estados Unidos permaneció estable pues, tras la renuncia ecuatoriana al ATPDEA en el 2013, no ha habido nuevos acercamientos. ${ }^{16}$ Pero el giro estratégico en lo político fomentó el restablecimiento de relaciones con organizaciones internacionales multilaterales. Además, las relaciones internacionales con otras potencias occidentales se han visto fortalecidas durante el año 2015. La búsqueda de nuevos socios comerciales, como Turquía, Bielorrusia y Tailandia, y la conservación de los actuales han sido una prioridad para el Ecuador. Sin embargo, aunque las nuevas relaciones económicas de Ecuador podrían haber reducido su dependencia de los Estados Unidos, estas podrían ahora representar lo que Gamso (2016) califica como una "diversificación de la dependencia económica". 


\section{Coyuntura política}

El campo político se vio marcado por la intensificación del antagonismo entre el oficialismo y la oposición. Correa continuó su intransigencia a la oposición, no solo dirigida a los políticos, sino a cualquier ciudadano que manifieste su inconformidad con el régimen. Asimismo, el oficialismo intensificó el control disciplinario de sus miembros (El Comercio, 2016a) y promovió la participación de las bases del movimiento Alianza País en distintos eventos de carácter público.

La intimidación política se dio de diversas maneras, desde la utilización de la función judicial, iniciada en sus instancias más bajas hasta el Tribunal Supremo, que se encuentra conformado casi exclusivamente por jueces afines a Alianza País (Basabe-Serrano y Llanos Escobar, 2014). Los procesos judiciales seguidos en contra de opositores del gobierno se dieron de forma frecuente, utilizando a los tribunales como un medio de amedrentamiento, y siguiendo el mismo patrón configurado hace varios años. ${ }^{17}$

El presidente Correa también efectuó las acusaciones contra sus opositores de forma directa, a través de redes sociales y principalmente en su programa sabatino. En dichos eventos reprendió de forma expresa a diversos usuarios de Twitter, que expresaban su inconformidad con su régimen (El Comercio, 2015j). El Presidente llamó a sus seguidores para intervenir activamente en las redes sociales bajo el eslogan: "somos más, muchísimos más" pretendiendo sacar del anonimato a usuarios de internet que criticaban al gobierno. ${ }^{18}$ La solicitud de Correa recibió una repuesta favorable, y al poco tiempo se reveló la identidad de varios usuarios de Twitter, quienes inmediatamente fueron atacados con amenazas personales. Así, la "Revolución Ciudadana" ha mostrado evidencias de ser cada vez más intolerante hacia cualquier crítica efectuada contra su gestión.

Además, durante el año 2015 salieron a la luz a través de WikiLeaks diversos correos electrónicos que implicaban al gobierno en la compra de software a la empresa italiana Hacking Team. Entonces, el gobierno fue acusado perseguir a sus opositores a través de su Secretaría de Inteligencia (El Universo, 2015e), mediante la utilización de utilidades informáticas que permitían capturar equipos de varios usuarios y vulnerar su seguridad. No obstante, la Secretaría de Inteligencia negó de forma rotunda la compra de dicho software. Pero el caso no ha sido completamente aclarado, pues a varios asambleístas de oposición, quienes ante la noticia se movilizaron a las dependencias de la SENAIN para tratar de investigar el caso, les fue negado el permiso para ingresar (El Universo, 2015g).

El panorama político se ha visto marcado por el inicio de las gestiones encaminadas a las elecciones generales del año 2017. Muchos partidos tradicionales han buscado reorganizarse a través de la generación de nuevos movimientos políticos o la reactivación

17 Un ejemplo claro se evidencia en el llamado a confesión judicial del periodista Roberto Aguilar Andrade (El Universo, 2015f).

18 El gobierno generó el portal web www.somosmas.ec, una especie de red social concebida para el registro y participación de sus simpatizantes. Uno de los casos más sonados fue la persecución efectuada en contra del usuario de redes denominado "crudo Ecuador", quien después de denunciar múltiples amenazas dejó las redes sociales. 
de los existentes. ${ }^{19}$ Otros líderes han efectuado campañas de movilización e intervención pública para posicionarse de cara a las comicios futuros. Se ha iniciado un incipiente movimiento de unidad opositora, en el que participan líderes regionales e inclusive antiguos partidarios del gobierno. ${ }^{20}$ Los nombres de los potenciales presidenciables han salido a la luz pública, y entre ellos se destaca a Guillermo Lasso, candidato presidencial durante el año 2013, Abdalá Bucaram Pulley, hijo del expresidente Abdalá Bucaram Ortiz; José Delgado, popular periodista ecuatoriano; y Washington Pesántez, exfiscal General del Estado (El Comercio, 2016b, 2016c).

\section{CAMBIOS INSTITUCIONALES}

Sin lugar a dudas las principales modificaciones institucionales del 2015 están contenidas en el paquete de 15 enmiendas constitucionales. ${ }^{21}$ Este fue aprobado en segundo debate el 3 de diciembre, con cien votos a favor, ocho en contra, y uno en blanco. Los cambios a la Constitución generaron gran controversia porque fueron aprobados a través de un proceso legislativo directo, y no mediante consulta popular.22 Con el aval de la Corte Constitucional se tramitaron a través de debates en la Asamblea Nacional donde Alianza País sostiene una mayoría absoluta. ${ }^{23}$ Pero además de la forma, el fondo de las enmiendas también generó rechazo, por su potencial para la restricción de derechos fundamentales de los ciudadanos, por el fortalecimiento de las prerrogativas del ejecutivo y por el potencial riesgo para el régimen democrático. Debido a esto, las enmiendas han sido sujeto de varias demandas de inconstitucionalidad (El Comercio, 2016d, 2016e).

Al final del plazo de 30 días para la presentación de demandas de inconstitucionalidad, se observaron ocho solicitudes de distintos entes: de la Contraloría General del Estado,

Por ejemplo, Abdalá Bucaram Pulley, exmiembro del antiguo Partido Roldosista Ecuatoriano, organizó un nuevo movimiento denominado Fuerza Ecuador. Este personaje ha anunciado su candidatura presidencial para el año 2017 (CNE, 2015). Además, la Izquierda Democrática, partido tradicional que perdió su personería jurídica, pretende su reinscripción en el Consejo Nacional Electoral, con el apoyo de su antiguo líder, Rodrigo Borja Cevallos (El Universo, 2015h).

20 El exsimpatizante del gobierno Ramiro González ha participado activamente en las reuniones convocadas por el movimiento de Unidad (El Universo, 2015i).

21 El paquete original de reformas contuvo un total de 16 enmiendas, sin embargo, una de ellas, relativa a la Defensoría del Pueblo, no fue aprobada.

22 La Constitución ecuatoriana establece dos formas de modificar el texto constitucional, reforma legislativa y referéndum. En el primer caso, el artículo 440 del texto constitucional prevé este tipo de proceder cuando vayan a ser modificadas partes no relativas a los elementos constitutivos del Estado. Por otra parte, la segunda opción es aplicable cuando se modifican elementos constitutivos del Estado. Aún así, existen las denominadas cláusulas pétreas (Hernández, 1993; Pedra, 2005), que no son objeto de reforma, y que requieren para su cambio la intervención del poder constituyente originario. El debate jurídico nacional ha considerado que este mecanismo no ha sido el idóneo para proceder con las reformas, por el contenido de las mismas. Pero la Corte Constitucional dio visto bueno para la procedencia de las modificaciones mediante este mecanismo.

23 La Asamblea Nacional contó con el apoyo de la Corte Constitucional, que avaló lo actuado mediante una revisión de las reformas de la Constitución. Dicha revisión se realizó en dos niveles, ex ante y ex post. En un inicio, el máximo tribunal constitucional verificó el contenido de las reformas a la Constitución propuesta. Finalmente, realizó también un control posterior, puesto que el texto original de las normas reformadas fue modificado por parte de la Asamblea Nacional durante el trámite legislativo. 
de Unidad Popular, del Parlamento Laboral, del Frente Unitario de Trabajadores, y de una asociación de jubilados, entre otros. ${ }^{24}$ Sin embargo, hasta el día de hoy la Corte Constitucional no se ha pronunciado. Además, existe incertidumbre sobre si la Corte Constitucional disfruta de la independencia necesaria para evaluar las demandas objetivamente. ${ }^{25}$ En este sentido, el resultado podría ser adverso a la oposición, inclusive, considerando que en el 2014 ya rechazó una demanda por inconstitucionalidad. ${ }^{26}$

¿Qué significa que las enmiendas procedan? (Ver enmiendas en Anexo 1) La principal enmienda del paquete es la que autoriza al Presidente de la República a reelegirse indefinidamente. En oposición a la retórica del oficialismo del pluralismo y la alternancia en el poder, basada principalmente en la prohibición de la reelección múltiple de autoridades, esta enmienda permitiría que el Presidente y otras autoridades de elección popular se mantengan en el poder por un plazo indeterminado. Aunque una disposición transitoria introducida a último momento por Rafael Correa postergó la entrada en vigencia de esta enmienda para después de los comicios de abril del 2017, la preocupación se mantiene respecto a la posibilidad de que la Corte Constitucional la anule y abra una vez más la ventana a la reelección. Sin embargo, se especula que Correa habría preferido abstenerse de buscar la reelección en el 2017 para evitar los costos políticos de la crisis económica y el desgaste de su partido.

Otra de las enmiendas que causó preocupación, por su potencial para la restricción de los derechos fundamentales de los ciudadanos, es el incremento de las atribuciones de las Fuerzas Armadas. La enmienda concede a las Fuerzas Armadas la facultad de participar en los operativos de seguridad interna y control del orden, prerrogativa exclusiva de la Policía previo a las enmiendas aprobadas. Avaladas por la Constitución, entonces, las Fuerzas Armadas podrían eventualmente intervenir en las jornadas de protestas, cuando el gobierno lo considere necesario.

Las consecuencias para el oficialismo son preocupantes, pues abren muchos escenarios políticos. Dado que la presencia de Correa es crucial para la unidad del movimiento personalista que es Alianza País (Polga-Hecimovich, 2014; De la Torre, 2013), ¿cuáles serán las posibilidades electorales del oficialismo en los comicios del 2017 donde Correa no participará como candidato presidencial? Algunos miembros de AP serían posibles sucesores, pero pesará sobre ellos la responsabilidad de no minar el proyecto político de Correa, y al mismo tiempo actualizarlo a la nueva realidad económica y política del país. Los problemas de sucesión se agravan en el contexto de la ausencia de los altos precios del petróleo que favorecieron a Correa en los últimos años.

24 Los procesos se identifican con los siguientes números: 99-15-IN, 100-15-IN, 102-15-IN, 01-16-IN, 03-16-IN, 04-16-IN, 05-16-IN, 08-14-IN. Pueden ser consultados en: www.corteconstitucional.gob.ec.

25 La Corte Constitucional está compuesta por nueve miembros designados por una comisión calificadora, conformada por dos miembros de la Función Ejecutiva, Legislativa y Participación Ciudadana y Control Social. Permanecen en sus funciones por el lapso de 3 años, y sus integrantes se renuevan por tercios cada tres años. La última corte constitucional fue designada durante el año 2012. Nuevos jueces accedieron a la magistratura durante el año 2015, en medio de constantes sospechas de vinculación con el ejecutivo (El Universo, 2015j). 
Finalmente, dos cambios institucionales que fueron debatidos ampliamente, pero que no se aprobaron pues los proyectos fueron retirados por el gobierno, son los correspondientes a la modificación de los regímenes tributarios de los impuestos a la herencia y plusvalía. Como ya se mencionó, las masivas protestas sociales en su contra señalaron que esta no sería una medida tan popular como el gobierno lo anticipó.

\section{RESULTADOS ELECTORALES}

Aunque durante el año 2015 no se produjeron procesos electorales mayores, es necesario hacer referencia a los resultados de las elecciones seccionales del año 2014. Este tópico es importante por la victoria de personajes de oposición en algunas de las principales ciudades del país, Guayaquil, Quito, Cuenca, Manta y Santo Domingo. Además, porque el presidente Correa fracasó en transmitir su carisma y popularidad a los candidatos del oficialismo (Polga-Hecimovich, 2014), a pesar de su activa participación en los comicios y del despliegue de la estructura partidista de AP. Algunos candidatos fracasaron por el bajo nivel de aprobación del gobierno -como en el caso de Quito- o por la existencia de una hegemonía de carácter tradicional -como el de Guayaquil.

Si bien en las elecciones generales del 2013, los partidos tradicionales parecían debilitarse frente a un AP que se consolidaba nacionalmente, con apoyo en 23 de las 24 provincias y 100 de los 137 curules en el legislativo, en el 2014 este panorama pareció revertirse. El principal competidor de AP en el 2013, CREO, ganó terreno en el 2014, con 18 alcaldías ganadas. Y AP disminuyó su número de alcaldes en comparación con el 2009, aunque se mantiene como la mayor fuerza política del país. Para un partido tan personalizado como Alianza País, cuyo apoyo legislativo depende de los coattails del presidente Correa, resultó muy difícil desempeñarse bien en las elecciones seccionales que no son concurrentes con las presidenciales.

El nivel de ausentismo en este proceso electoral fue alto, reportándose una participación estimada del $83 \%$ del padrón electoral. ${ }^{27}$ En este punto, es importante tomar en cuenta que todos los ecuatorianos, entre 18 y 65 años de edad, deben ejercer el sufragio de manera obligatoria.

En general, los resultados de las elecciones del año 2014 generaron una nueva configuración del poder territorial. En las capitales municipales de las provincias, AP consiguió la victoria en cuatro municipios, junto a tres alcaldías alcanzadas del movimiento aliado Avanza. En los Consejos Provinciales, el oficialismo obtuvo un mayor número de locaciones, sin embargo, la oposición también incrementó su participación. Así, el oficialismo y la oposición ganaron diez prefecturas cada una, y los movimientos regionales controlan las demás. 
Tabla 1. Resultados electorales

\begin{tabular}{|c|c|c|c|c|c|c|}
\hline & $\begin{array}{c}\text { Alcaldías } \\
2009\end{array}$ & $\begin{array}{c}\text { Alcaldías } \\
2014\end{array}$ & Cambio & $\begin{array}{l}\text { Prefecturas } \\
2009\end{array}$ & $\begin{array}{c}\text { Prefecturas } \\
2014\end{array}$ & Cambio \\
\hline & $\%$ & $\%$ & $\%$ & $\mathrm{~N}$ & $\mathrm{~N}$ & $\mathrm{~N}$ \\
\hline Alianza PAIS & 32,58 & 30,77 & $-1,81$ & 9 & 10 & 1 \\
\hline Avanza & 0,00 & 15,38 & 15,38 & 0 & 1 & 1 \\
\hline Pachakutik & 11,76 & 10,41 & $-1,36$ & 4 & 3 & -1 \\
\hline CREO & 0,00 & 8,14 & 8,14 & 0 & 1 & 1 \\
\hline SUMA & 0,00 & 6,79 & 6,79 & 0 & 2 & 2 \\
\hline PSP & 13,57 & 4,07 & $-9,50$ & 3 & 1 & -2 \\
\hline $\begin{array}{l}\text { Movimiento } \\
\text { Popular } \\
\text { Democrático }\end{array}$ & 4,52 & 1,36 & $-3,17$ & 1 & 2 & 1 \\
\hline Otros & 37,56 & 23,08 & $-14,48$ & 6 & 3 & -3 \\
\hline Total & 100,00 & 100,00 & & 23 & 23 & \\
\hline
\end{tabular}

Fuente: CNE y Borja (2014).

Las principales derrotas del oficialismo se suscitaron en las ciudades de Quito y Cuenca, que previamente se encontraban en manos del AP. La alcaldía de Quito fue obtenida por Mauricio Rodas, político que se lanzó a la esfera pública a través de las elecciones generales del año 2013 mediante su propio movimiento SUMA. Mientras que el municipio de la ciudad de Cuenca quedó en manos de Marcelo Cabrera, quien obtuvo su cargo a través de su movimiento regional Democracia Directa, venciendo a Paúl Granda de AP con $50,6 \%$ versus $44,9 \%$. El caso de Cuenca golpea muy fuertemente al oficialismo pues esta ciudad era altamente afín al gobierno.

Por otra parte, en la ciudad de Guayaquil, la candidata del oficialismo, Viviana Bonilla, aunque logró un buen porcentaje de votos (40\% aproximadamente), no logró vencer al alcalde Nebot (60\% aproximadamente), quien ha gobernado la ciudad desde el año 2000.

\section{PODER EJECUTIVO}

\section{Composición y rotación del gabinete}

Ecuador es uno de los países con ministros de menor duración en América Latina. Los miembros del gabinete en Ecuador se mantienen en funciones apenas un sexto del 
tiempo del mandato presidencial, muy por debajo del ministro promedio regional que se mantiene un tercio de este tiempo (Martínez-Gallardo, 2014).

Este panorama no mejoró de manera sustancial durante el gobierno de Rafael Correa. Según Basabe-Serrano, Polga-Hecimovich y Mejía Acosta (2013), un ministro promedio de Correa dura 366 días, solo 29 días más que el promedio durante el período 19982008 (337 días), que se destaca por su extrema inestabilidad, con Presidentes como Abdalá Bucaram, Jamil Mahuad, o Lucio Gutiérrez, que no concluyeron su mandato. La continuidad del alto nivel de volatilidad de los ministros durante el mandato de Correa llama la atención, dado que ha contado con una mayoría en el poder legislativo y altos niveles de popularidad, lo que debería haber favorecido la permanencia de los ministros.

En el 2015 el nivel de volatilidad de los ministros que caracteriza a Ecuador no ha disminuido. Así, en este año se produjeron diecinueve salidas de ministros, entre renuncias, destituciones y rotaciones, un patrón similar a años anteriores (Basabe-Serrano y Martínez, 2014). A pesar del intenso recambio de ministros, Rafael Correa y su régimen sostuvieron su monopolio político del gabinete, dado que la mayoría de los ministros nombrados durante 2015 poseen trayectorias de servicio público en el Ejecutivo o son miembros de Alianza País.

Entre febrero y marzo del 2015 se dieron seis cambios, de los cuales cuatro fueron rotaciones entre ministerios ${ }^{28} \mathrm{o}$ casos de retornos al gabinete después de un período fuera. ${ }^{29} \mathrm{La}$ crisis del gabinete de octubre del 2015 se produjo por dos renuncias sorpresivas, la de Pabel Muñoz de la SEPLANDES y la de Nathalie Cely del Ministerio de Producción. Finalmente, de los ocho cambios ministeriales entre octubre y noviembre, tres fueron rotaciones dentro del gabinete presidencial, ${ }^{30} \mathrm{y}$ los otros cinco fueron exfuncionarios del gobierno. ${ }^{31}$

Diego Aulestia dejó el Ministerio de Vivienda y entró al de Comercio y Guillaume Jean Long dejó el de Conocimiento y entró al de Cultura.

29 María de los Ángeles Duarte entró al de Vivienda y Nathalie Cely volvió al de Producción. Salieron José Francisco Cevallos (Ministro de Deportes), Francisco Rivadeneira (Ministro de Comercio Exterior), Diego Aulestia (Ministerio de Desarrollo Urbano y Vivienda), Richard Espinosa (Ministerio Coordinador de la Producción), Guillaume Jean (Ministerio Coordinador de Conocimiento y Talento Humano), y Francisco Borja (Ministerio de Cultura).

30 Sandra Naranjo (salió del ministerio de Turismo para entrar al SEPLANDES), Fernando Alvarado (salió de la Secretaria de la Comunicación para ocupar el Ministerio de Turismo, y Vinicio Alvarado salió de la Secretaria Nacional de Administración Pública y pasó a ocupar el Ministerio Coordinador de la Producción).

31 Por ejemplo, Pedro Solines (nuevo ministro de la Secretaría Nacional de Administración Pública) lideraba la Secretaría Técnica de Transparencia de Gestión, Patricio Barriga (nuevo ministro de la Secretaría Nacional de Comunicación) había sido el representante del Presidente ante el Consejo de Regulación y Desarrollo de la Información y Comunicación, Daniel Ortega (nuevo ministro del Ministerio del Ambiente) se había desempeñado en múltiples altos cargos en el Ministerio de Relaciones Exteriores, Renato Barrezueta (nuevo ministro de Trabajo) había sido designado gobernador Azuay en el 2014, y Xavier Mauricio Enderica (nuevo ministro de Deportes) había liderado la Coordinación Regional de la Zona 6 del Ministerio del Deporte. 
Tabla 2. Cambios en gabinete

\begin{tabular}{|c|c|c|c|c|c|c|}
\hline Ministerio & $\begin{array}{l}\text { Ministro } \\
\text { saliente }\end{array}$ & $\begin{array}{l}\text { Fecha } \\
\text { entrada }\end{array}$ & $\begin{array}{l}\text { Fecha } \\
\text { salida }\end{array}$ & $\begin{array}{l}\text { Destino del } \\
\text { ministro }\end{array}$ & $\begin{array}{l}\text { Ministro } \\
\text { entrante }\end{array}$ & $\begin{array}{l}\text { Fecha } \\
\text { entrada }\end{array}$ \\
\hline Ministerio del Deporte & $\begin{array}{l}\text { José Francisco } \\
\text { Cevallos }\end{array}$ & $11 / 24 / 11$ & $10 / 8 / 14$ & Función Privada & $\begin{array}{l}\text { Catalina } \\
\text { Ontaneda Vivar }\end{array}$ & $2 / 13 / 15$ \\
\hline Ministerio de Minería ${ }^{34}$ & - & - & - & - & $\begin{array}{l}\text { Javier Córdova } \\
\text { Unda }\end{array}$ & $2 / 13 / 15$ \\
\hline $\begin{array}{l}\text { Ministerio de Comercio } \\
\text { Exterior }\end{array}$ & $\begin{array}{l}\text { Francisco } \\
\text { Rivadeneira } \\
\text { Sarzosa }\end{array}$ & $6 / 19 / 13$ & $2 / 18 / 15$ & $\begin{array}{l}\text { Representante } \\
\text { del Ecuador ante } \\
\text { el FMI }\end{array}$ & $\begin{array}{l}\text { Diego Aulestia } \\
\text { Valencia }\end{array}$ & $2 / 18 / 15$ \\
\hline $\begin{array}{l}\text { Ministerio de } \\
\text { Desarrollo Urbano y } \\
\text { Vivienda }\end{array}$ & $\begin{array}{l}\text { Diego Aulestia } \\
\text { Valencia }\end{array}$ & $12 / 5 / 13$ & $2 / 18 / 15$ & $\begin{array}{l}\text { Ministerio } \\
\text { de Comercio } \\
\text { Exterior }\end{array}$ & $\begin{array}{l}\text { María de los } \\
\text { Ángeles Duarte }\end{array}$ & $2 / 18 / 15$ \\
\hline $\begin{array}{l}\text { Ministerio Coordinador } \\
\text { de la Producción }\end{array}$ & $\begin{array}{l}\text { Richard Espinoza } \\
\text { Guzmán }\end{array}$ & $4 / 10 / 13$ & $3 / 23 / 15$ & $\begin{array}{l}\text { Presidente del } \\
\text { IESS }\end{array}$ & $\begin{array}{l}\text { Nathalie Cely } \\
\text { Suárez }\end{array}$ & $3 / 23 / 15$ \\
\hline Ministerio de Cultura & $\begin{array}{l}\text { Francisco Borja } \\
\text { Cevallos }\end{array}$ & $9 / 15 / 14$ & $3 / 26 / 15$ & $\begin{array}{l}\text { Embajador del } \\
\text { Ecuador en USA }\end{array}$ & $\begin{array}{l}\text { Guillaume Jean } \\
\text { Long } 35\end{array}$ & $3 / 26 / 15$ \\
\hline $\begin{array}{l}\text { Ministerio Coordinador } \\
\text { de Conocimiento y } \\
\text { Talento Humano }\end{array}$ & $\begin{array}{l}\text { Guillaume Jean } \\
\text { Long }\end{array}$ & $5 / 8 / 13$ & $3 / 26 / 15$ & $\begin{array}{l}\text { Ministerio de } \\
\text { Cultura }\end{array}$ & $\begin{array}{l}\text { Andrés Arauz } \\
\text { Galarza }\end{array}$ & $3 / 26 / 15$ \\
\hline $\begin{array}{l}\text { Ministerio de Industrias } \\
\text { y Productividad }\end{array}$ & $\begin{array}{l}\text { Ramiro González } \\
\text { Jaramillo }\end{array}$ & $5 / 3 / 13$ & $4 / 14 / 15$ & Función privada & Miguel Egas Peña & $4 / 29 / 15$ \\
\hline $\begin{array}{l}\text { Ministerio de } \\
\text { Transporte y Obras } \\
\text { Públicas }\end{array}$ & Paola Carvajal & $3 / 10 / 14$ & $6 / 22 / 15$ & No identificado & $\begin{array}{l}\text { Walter Solís } \\
\text { Valarezo }\end{array}$ & $6 / 22 / 15$ \\
\hline Secretaría del Agua & $\begin{array}{l}\text { Walter Solís } \\
\text { Valarezo }\end{array}$ & $11 / 10 / 11$ & $6 / 22 / 15$ & $\begin{array}{l}\text { Ministerio de } \\
\text { transporte y } \\
\text { obras públicas }\end{array}$ & $\begin{array}{l}\text { Carlos Bernal } \\
\text { Alvarado }\end{array}$ & $6 / 22 / 15$ \\
\hline Ministerio del Trabajo & $\begin{array}{l}\text { Carlos Marx } \\
\text { Carrasco }\end{array}$ & $3 / 13 / 14$ & $11 / 19 / 15$ & No identificado & $\begin{array}{l}\text { Renato } \\
\text { Barrezueta } \\
\text { Carrión }\end{array}$ & $11 / 19 / 15$ \\
\hline $\begin{array}{l}\text { Secretaría Nacional de } \\
\text { Comunicación }\end{array}$ & $\begin{array}{l}\text { Fernando } \\
\text { Alvarado Espinel }\end{array}$ & $6 / 23 / 09$ & $11 / 19 / 15$ & $\begin{array}{l}\text { Ministerio de } \\
\text { Turismo }\end{array}$ & $\begin{array}{l}\text { Patricio Barriga } \\
\text { Jaramillo }\end{array}$ & $11 / 19 / 15$ \\
\hline Ministerio de Ambiente & $\begin{array}{l}\text { Gladys Lorena } \\
\text { Tapia Núñez }\end{array}$ & $11 / 28 / 12$ & $11 / 19 / 15$ & No identificado & $\begin{array}{l}\text { Daniel Ortega } \\
\text { Pacheco }\end{array}$ & $11 / 19 / 15$ \\
\hline Ministerio del Deporte & $\begin{array}{l}\text { Catalina } \\
\text { Ontaneda Vivar }\end{array}$ & $2 / 13 / 15$ & $11 / 19 / 15$ & No identificado & $\begin{array}{l}\text { Xavier Mauricio } \\
\text { Enderica Salgado }\end{array}$ & $11 / 19 / 15$ \\
\hline Ministerio de Turismo & $\begin{array}{l}\text { Sandra Naranjo } \\
\text { Bautista }\end{array}$ & $7 / 21 / 14$ & $10 / 15 / 15$ & No identificado & $\begin{array}{l}\text { Fernando } \\
\text { Alvarado Espinel }\end{array}$ & $11 / 19 / 15$ \\
\hline $\begin{array}{l}\text { Secretaría Nacional } \\
\text { de la Administración } \\
\text { Pública }\end{array}$ & $\begin{array}{l}\text { Vinicio Alvarado } \\
\text { Espinel }\end{array}$ & $3 / 10 / 14$ & $10 / 15 / 15$ & $\begin{array}{l}\text { Ministerio } \\
\text { Coordinador de } \\
\text { la Producción }\end{array}$ & $\begin{array}{l}\text { Pedro Solines } \\
\text { Chacón }\end{array}$ & $10 / 15 / 15$ \\
\hline $\begin{array}{l}\text { Ministerio Coordinador } \\
\text { de la Producción }\end{array}$ & $\begin{array}{l}\text { Nathalie Cely } \\
\text { Suárez }\end{array}$ & $3 / 23 / 15$ & $10 / 15 / 15$ & Función privada & $\begin{array}{l}\text { Vinicio Alvarado } \\
\text { Espinel }\end{array}$ & $10 / 15 / 15$ \\
\hline $\begin{array}{l}\text { Secretaría Nacional } \\
\text { de Planificación y } \\
\text { Desarrollo }\end{array}$ & $\begin{array}{l}\text { Christian Pabel } \\
\text { Muñoz López }\end{array}$ & $8 / 13 / 13$ & $10 / 15 / 15$ & No identificado & $\begin{array}{l}\text { Sandra Naranjo } \\
\text { Bautista }\end{array}$ & $10 / 15 / 15$ \\
\hline
\end{tabular}

Fuente: Presidencia de la República del Ecuador.

32 Ministerio creado mediante Decreto Ejecutivo No. 578 de 13 de febrero de 2015. Disponible en: www.presidencia. gob.ec.

33 Durante el mes de marzo de 2016, Guillaume Long pasó a ejercer el cargo de ministro de Relaciones Exteriores, mientras que Ricardo Patiño asumió el Ministerio de Defensa. Por su parte, Fernando Cordero, extitular de la cartera de defensa se retiró a funciones privadas. 
Si analizamos las razones de las salidas y rotaciones en conjunto, encontramos que supuestamente en su mayoría estuvieron relacionadas con la habilidad del gobierno para enfrentar la crisis económica (Martínez-Gallardo, 2005), aunque en algunos casos respondieron a la necesidad del Presidente de limitar las amenazas a su popularidad y poder (Basabe-Serrano et al., 2013). Por ejemplo, la salida de Nathalie Cely y de Ramiro González en dos momentos distintos fueron consecuencia de diferencias con el Presidente. En el caso de Cely, la salida se debió probablemente en parte a su postura más abierta en la discusión con los sectores empresariales del país, en particular con lo referido al proyecto de Ley Incentivo para Asociaciones Público-Privadas. En el caso de González abiertamente por su rechazo (y el de su partido Avanza) a las reformas de la seguridad social impulsadas por el oficialismo (El Comercio, 2015k).

\section{Análisis del funcionamiento del gabinete}

El gabinete ministerial está compuesto por 28 ministerios y 8 secretarías de rango similar a los ministerios. Del total de ministerios, 6 son coordinadores y 22 son sectoriales. En relación a las secretarías, 4 son secretarías nacionales y 4 son secretarías técnicas (ver Figura 5). Bajo el gobierno de Correa, en los últimos 9 años, se han creado un número importante de ministerios supuestamente para adaptar la burocracia a la función ampliada del Estado en la sociedad. Como indica Polga Hecimovich (2013), en la práctica, los Ministerios de Coordinación son una capa burocrática adicional del Estado Ecuatoriano creada por Correa.

Según el organigrama de la función ejecutiva, los ministerios ordinarios están subordinados a los ministerios coordinadores, que agrupan dos o cuatro de ellos -con la excepción del Ministerio de Coordinación de la Política Económica que solo dirige al Ministerio de Finanzas. La complejidad del gabinete Ecuatoriano solo facilita la primacía del presidente Correa, cuyo estilo personalista y populista se ha documentado en repetidas

Figura 6. Organización de la función ejecutiva

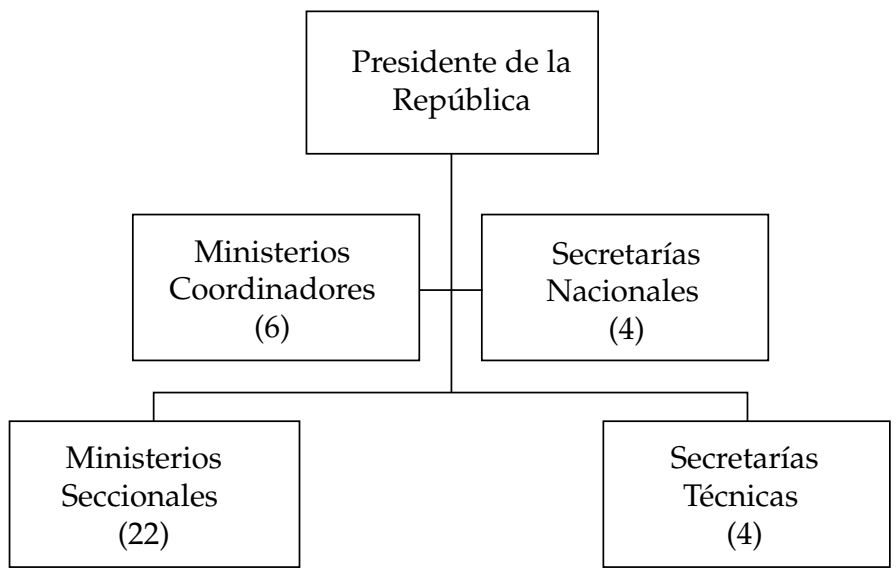

Fuente: Estatuto del Régimen Jurídico Administrativo de la Función Ejecutiva y SENPLADES. 
oportunidades (Freidenberg, 2015; Pachano, 2010). Como indican Basabe-Serrano y Martínez (2014), la política de gobierno comienza y termina en la oficina del Presidente.

En el 2015 se creó el Ministerio de Minería que responde a la reorganización de las competencias del Ministerio de Recursos Naturales No Renovables. El antiguo ministerio asumió competencias exclusivas en el ámbito de petróleo y el gas, cambiando su nombre a Ministerio de Hidrocarburos. ${ }^{34} \mathrm{Y}$ las funciones ministeriales para recursos que no son hidrocarburos pasaron a la jurisdicción del nuevo Ministerio de Minería. ${ }^{35}$

En cuanto al funcionamiento interno de la toma de decisiones en el gabinete es probable que los debates de política pública estén circunscritos a la línea de gobierno de Correa. Con una composición mayoritaria de ministros afines al oficialismo todo indica que el pluralismo en el gabinete es reducido. Además, la salida de algunos ministros en el 2015 por discrepancias con el Presidente son ilustrativas de esta dinámica. Aunque la mayoría que AP sostiene en la Asamblea Nacional hace innecesario compartir el poder con otros sectores políticos para gobernar, el pluralismo limitado practicado por Correa no termina en el funcionamiento del gabinete. La intolerancia al pluralismo se extiende también al constante acoso e intimidación de los críticos del gobierno. Dentro de la política formal como afuera de esta, en contra de periodistas, caricaturistas, y bloggers hasta académicos, usuarios de redes sociales y ciudadanos ordinarios. ${ }^{36}$

\section{Estilos presidenciales}

El estilo personalista y confrontacional del presidente Correa ha marcado la política ecuatoriana de los últimos nueve años. La llamada "Revolución Ciudadana", en efecto, tuvo el ímpetu de un líder que no acepta críticas. Sus constantes ataques a los medios de comunicación, a través de sus sabatinas y de sanciones administrativas basadas en la Ley de Comunicación, son muestra de su voluntad para suprimir la libertad de prensa y la libertad de expresión. ${ }^{37}$

Esta dimensión del gobierno de Correa es la que más costos políticos podría traerle en el año electoral del 2017 y después. No solo porque un sector social y político, que ya se opone enérgicamente a la restricción de sus libertades ciudadanas, podría alcanzar apoyo popular para confrontar a quien sea el candidato de Alianza País. Sino además porque la negativa del Presidente a escuchar a los opositores y dar espacio a la critica y la reflexión podrían haber dejado a la "Revolución Ciudadana" anacrónica, huérfana de aliados, y faltante de una institucionalización política que la sostenga frente a la crisis que hoy enfrenta el país.

34 Creado mediante Decreto Ejecutivo \# 578 de abril del 2015.

35 Anteriormente, el organismo rector del sector minero era el Viceministerio de Minería, adscrito al Ministerio de Recursos Naturales no Renovables (actualmente Ministerio de Hidrocarburos)

36 Según el informe de Freedom House 2015, la ONG Fundamedios reportó que hubo 253 casos de acoso verbal, físico o legal a periodistas durante ese año.

37 Cabe mencionar que la regulación estatal de los medios de comunicación se planteó inicialmente como respuesta a la alta concentración de los medios en manos de unas cuantas familias y conglomerados económicos. Como lo documenta Kitzberger (2016): “Dos periódicos representaban aproximadamente 65 por ciento de la circulación nacional: el Grupo Pérez de El Universo, representando a las élites políticas y económicas de Guayaquil, y el tradicional El Comercio de Quito, perteneciente a la familia Mantilla". 


\section{PODER LEGISLATIVO}

El legislativo mantuvo una labor discreta a lo largo del año 2015, con una producción total de 15 leyes. Su funcionamiento se ha sujetado a las instrucciones del ejecutivo, sin existir una verdadera independencia en sus funciones. El Ejecutivo presentó 11 de las 15 leyes aprobadas. Del total de los 81 proyectos de ley presentados ante la Asamblea en el 2015, casi el 30\% fueron presentados por el oficialismo. Es decir, el grueso de la legislación es producida por el ejecutivo directamente o a través de la bancada del oficialismo.

Tabla 3. Leyes aprobados durante $2015^{38}$

\begin{tabular}{|c|c|c|c|c|}
\hline $\mathrm{N}$ & Nombre de la Ley & $\begin{array}{c}\text { Fecha de } \\
\text { aprobación }{ }^{40}\end{array}$ & $\begin{array}{l}\text { Fecha de } \\
\text { publicación }\end{array}$ & Iniciativa \\
\hline 1 & $\begin{array}{l}\text { Ley Orgánica de Incentivos para Asociaciones } \\
\text { Público-Privadas y la Inversión Extranjera }\end{array}$ & $15 / 12 / 2015$ & $18 / 12 / 2015$ & Función ejecutiva \\
\hline 2 & $\begin{array}{l}\text { Ley Orgánica de Prevención Integral del Fenómeno } \\
\text { Socio Económico de las Drogas y de Regulación } \\
\text { y Control del Uso de Sustancias Catalogadas } \\
\text { Sujetas a Fiscalización }\end{array}$ & $01 / 10 / 2015$ & $26 / 10 / 2015$ & $\begin{array}{l}\text { Comisión legislativa } \\
\text { (Carlos Velasco, AP) }\end{array}$ \\
\hline 3 & Ley General de Servicios Postales & $24 / 09 / 2015$ & $07 / 10 / 2015$ & Función ejecutiva \\
\hline 4 & $\begin{array}{l}\text { Ley Orgánica Reformatoria al Código Orgánico } \\
\text { Integral Penal }\end{array}$ & $24 / 09 / 2015$ & $30 / 09 / 2015$ & Comisión legislativa \\
\hline 5 & $\begin{array}{l}\text { Ley Reformatoria a la Ley Orgánica de Educación } \\
\text { Intercultural }\end{array}$ & $18 / 08 / 2015$ & $25 / 08 / 2015$ & Función ejecutiva \\
\hline 6 & Ley Reformatoria del Código Civil & $16 / 06 / 2015$ & $19 / 06 / 2015$ & $\begin{array}{l}\text { Comisión legislativa } \\
\text { (Silvia Salgado, PS-FA) }\end{array}$ \\
\hline 7 & $\begin{array}{l}\text { Ley Orgánica de Régimen Especial de la Provincia } \\
\text { de Galápagos }\end{array}$ & $09 / 06 / 2015$ & $11 / 06 / 2015$ & Función ejecutiva \\
\hline 8 & Código Orgánico General de Procesos & $12 / 05 / 2015$ & $22 / 05 / 2015$ & $\begin{array}{l}\text { Función judicial } \\
\text { (Gustavo Jalkh) }\end{array}$ \\
\hline 9 & $\begin{array}{l}\text { Ley Orgánica de Remisión de Intereses, Multas } \\
\text { y Recargos }\end{array}$ & $28 / 04 / 2015$ & $05 / 05 / 2015$ & Función ejecutiva \\
\hline 10 & $\begin{array}{l}\text { Ley Orgánica para la Justicia Laboral y } \\
\text { Reconocimiento de Trabajo en el Hogar }\end{array}$ & $14 / 04 / 2015$ & $20 / 04 / 2015$ & Función ejecutiva \\
\hline 11 & $\begin{array}{l}\text { Ley Reformatoria a la Ley Constitutiva del Instituto } \\
\text { Nacional de Investigaciones Agropecuarias } \\
\text { (INIAP) y Derogatoria de la Ley Especial del } \\
\text { Sector Cafetero }\end{array}$ & $27 / 11 / 2014$ & $26 / 02 / 2015$ & Función ejecutiva \\
\hline 12 & $\begin{array}{l}\text { Ley Reformatoria a la Ley de Personal de las } \\
\text { Fuerzas Armadas }\end{array}$ & $10 / 02 / 2015$ & $20 / 02 / 2015$ & Función ejecutiva \\
\hline 13 & $\begin{array}{l}\text { Ley de Reconocimiento Público del Estado en las } \\
\text { Áreas Cultural, Científica y Deportiva }\end{array}$ & $20 / 01 / 2015$ & $20 / 02 / 2015$ & $\begin{array}{l}\text { Comisión legislativa } \\
\text { (Ximena Ponce, AP) }\end{array}$ \\
\hline 14 & Ley Orgánica de Telecomunicaciones & $10 / 02 / 2015$ & $18 / 02 / 2015$ & Función ejecutiva \\
\hline 15 & $\begin{array}{l}\text { Ley Orgánica del Servicio Público de Energía } \\
\text { Eléctrica }\end{array}$ & $08 / 01 / 2015$ & $16 / 01 / 2015$ & Función ejecutiva \\
\hline
\end{tabular}

Fuentes: Asamblea Nacional y Observatorio Legislativo. 
El legislativo, desde las elecciones generales del año 2013, es controlado por el partido oficialista, que ostenta una mayoría superlativa. De esta forma, el oficialismo no requiere negociar, estableciendo la agenda de la Asamblea Nacional unilateralmente. Sin embargo, la Asamblea Nacional sí ha contado con la acción de opositores, pero que ejercen una oposición simbólica, sin la capacidad de aprobar sus iniciativas y proyectos dentro del legislativo. Así, el rol de los asambleístas ha tomado distintas fórmulas de acción, desde la asociación con figuras públicas que han representado los intereses de la oposición y un sector de la ciudadanía en las calles, hasta convocatorias efectuadas mediante redes sociales, que han facilitado la articulación de movilizaciones pacíficas.

De la misma forma, se observa que el partido oficialista controla todas las comisiones legislativas. Esta estrategia oficialista contribuye a la concentración de las preferencias en un mismo círculo, evitando una mayor distribución del poder y la presencia de filtros institucionales más complejos (Tsebelis, 2002). Principalmente, resulta importante mencionar el control oficialista de la Comisión de Fiscalización, que ha dificultado la fiscalización del gobierno. ${ }^{39} \mathrm{~A}$ su vez, dentro del legislativo se evidencia un fuerte control de la disciplina partidista de parte del movimiento oficialista. Un caso recordado constituye la sanción interna al legislador Fernando Bustamante (El Telégrafo, 2015c; El Comercio, 2016f), por su abstención en la votación final mediante la cual se aprobó el paquete de reformas constitucionales. ${ }^{40}$ Esto es evidencia de las medidas disciplinarias que recaen en contra de quienes se apartan de las lógicas del bloque.

\section{Tabla 4. Comisiones legislativas de la Asamblea Nacional}

\begin{tabular}{llc}
\hline \multicolumn{1}{c}{ Comisión } & \multicolumn{1}{c}{ Presidente } & Partido \\
\hline Ocasional de Enmienda Constitucional ${ }^{43}$ & Juan Carlos Cassinelli & AP \\
De Justicia y Estructura del Estado & Mauro Edmundo Andino Reinoso & AP \\
De los Derechos de los Trabajadores y Seguridad Social & Anny Marllely Vásconez Ortega & AP \\
Del Régimen Económico y Tributario y su Regulación y Control & Virgilio Humberto Hernández Enríquez & AP \\
Del Desarrollo Económico, Productivo y la Microempresa & Lídice Vanessa Larrea Viteri & AP \\
De Soberanía, Integración, Relaciones Internacionales y Seguridad & Fernando Xavier Bustamante Ponce ${ }^{44}$ & AP \\
De la Biodiversidad y Recursos Naturales & Carlos Eloy Viteri Gualinga & AP \\
De la Soberanía Alimentaria y Desarrollo del Sector Agropecuario y Pesquero & Miguel Ángel Carvajal Aguirre & AP \\
De los Gobiernos Autónomos, Descentralización, Competencias y Organización Territorial & Richard Oswaldo Calderón Saltos & AP \\
De Educación, Cultura, Ciencia y Tecnología & Raúl Eugenio Abad Vélez & AP \\
Del Derecho a la Salud & William Antonio Garzón Ricaurte & AP \\
De Participación Ciudadana y Control Social & Alex Fabián Solano Moreno & AP \\
De los Derechos Colectivos Comunitarios y la Interculturalidad & Zobeida Guisela Gudiño Mena & AP \\
De Fiscalización y Control Político & María José Carrión Cevallos & AP \\
\hline
\end{tabular}

Fuente: Asamblea Nacional.

39 Sin sorpresa encontramos que se reportaron cero procesos de juicio político-impeachment-suscitados dentro de la Asamblea Nacional durante el mandato de Rafael Correa.

$40 \quad$ Estos procesos de sanción a los asambleístas de Alianza País que se han separado de su bloque durante una votación ya se habían presentado en años anteriores, particularmente en el caso de las asambleístas a favor del aborto.

41 Aunque esta comisión tuvo el carácter de ocasional, se incluye por su relevancia en el contexto político ecuatoriano.

42 Durante el año 2016 Fernando Bustamante dejó su cargo como presidente de la comisión de soberanía, integración, relaciones internacionales y seguridad. La posición fue asumida por la asambleísta María Augusta Calle, miembro del bloque de Alianza País. 
Como puede observarse en la Tabla 4, a pesar de que la participación de asambleístas mujeres en el legislativo es del $43,07 \%$, los cargos de decisión son ejercidos principalmente por hombres. ${ }^{43}$ En este sentido, apenas 4 de las 14 presidencias de las comisiones legislativas son ejercidas por mujeres $(28,6 \%)$.

Aunque ya se mencionó que el evento más importante del legislativo en el 2015 fue la aprobación de las enmiendas constitucionales, también se aprobaron algunas reformas legislativas de importancia. Por ejemplo, el paquete de reformas laborales, que modificó el régimen laboral general del país, siendo una de sus principales medidas la eliminación de los contratos a plazo fijo y estableciendo el contrato de plazo indefinido como la modalidad laboral por defecto; el Código Orgánico General de Procesos, que reformó la normativa procesal para todo tipo de procesos judiciales, exceptuando los correspondientes al ámbito penal; y la emisión de la Ley Orgánica de Telecomunicaciones, que alteró de forma sustancial el régimen aplicable a esta materia, inclusive, cambiando las regulaciones referentes a sus entes de control. En todos los casos, estas reformas modificaron partes sustanciales de la legislación ecuatoriana.

\section{RELACIÓN ENTRE PODERES DEL ESTADO}

A lo largo del año 2015, la relación entre poderes del Estado se definió por la constante injerencia del Ejecutivo en las tareas del Legislativo y el Judicial. ${ }^{44}$ La función judicial ha sido continuamente utilizada por parte del ejecutivo para el amedrentamiento de opositores políticos. Hay reportes de cómo los detractores del régimen de Correa han sido convocados ante organismos judiciales, con el fin de que rindan declaraciones, o simplemente para enjuiciarlos por distintas conductas que son judicializadas. ${ }^{45}$

Además, el hecho que el organismo administrativo y disciplinario de la Función Judicial, El Consejo de la Judicatura, sea dirigido por Gustavo Jalkh, funcionario cercano al presidente Correa, abona a la evidencia en favor de tal injerencia (Basabe-Serrano y Llanos, 2014). Dada la fortaleza del Presidente, marcada por su sólida bancada legislativa, sus altos niveles de aprobación, y el elevado gasto público, es probable que este haya tenido facilidad para incidir en la composición de la Corte Suprema directamente. De hecho, el 77\% de los jueces supremos son considerados cercanos a AP (Basabe-Serrano y Llanos Escobar, 2014). Es posible que esta situación favorezca la captura de la Función Judicial por el Poder Ejecutivo, dificultando el desempeño independiente de sus funciones (Basabe-Serrano, Pachano, y Mejía Acosta, 2010; Sanchez Urribarri, 2011).

En el caso del poder legislativo, reiteramos que el oficialismo cuenta con una amplia mayoría oficialista, con una fuerza oficialista sumamente disciplinada (con sanciones por indisciplina que se han materializado en varios casos), y con el dominio de todas

43 La legislación ecuatoriana establece disposiciones que promueven la representación igualitaria de hombres y mujeres en la Asamblea Nacional (Artículos 3 y 4 de la Ley Orgánica Electoral "Código de la Democracia”). Además, aunque con menor relevancia, se han denunciado intervenciones del ejecutivo sobre los dos poderes creados durante el gobierno de Correa-Poder Electoral y Participación Ciudadana.

45 Ver sección de coyuntura social para mayor detalle sobre los casos. 
las comisiones legislativas. Todo esto sugiere que la agenda del legislativo puede ser fácilmente manipulada por el ejecutivo, que junto con su poder de veto, ha conseguido modelar la legislación nacional de conformidad con sus proyectos políticos.

\section{RELACIÓN ENTRE DISTINTOS NIVELES DE GOBIERNO}

En las elecciones regionales de febrero del 2014, el presidente Correa perdió su fortaleza en varias ciudades principales. El debate por las competencias en los servicios de transporte público y tránsito es ilustrativo del nuevo balance de poder territorial. El gobierno central alegó que la gestión de este sector es de incumbencia exclusiva de los gobiernos seccionales municipales. Entonces, procedió a retirar su participación en estas actividades y transfirió fondos a los gobiernos seccionales para que asuman de forma directa ambas temáticas.

La decisión se tomó en el contexto del debate relativo al alza de pasajes del transporte público, que hasta el año 2015 se encontraba subsidiado, y cuyas tarifas no fueron incrementadas por el lapso de once años. Así, el gobierno central evitó la compleja situación de anunciar el aumento de las tarifas, y transfirió dicha responsabilidad a los gobiernos seccionales. En muchos casos, lo municipios optaron por el incremento de las tarifas del transporte público, lo que generó una reacción negativa por parte de la ciudadanía. Esta medida originó la redirección de los reclamos de los transportistas hacia los municipios, conservando el apoyo del sector al oficialismo (El Comercio, 20151).

Sin embargo, algunas municipalidades rechazaron la decisión del gobierno y se negaron a encargarse directamente de estas temáticas. Incluso, el alcalde Nebot de Guayaquil decidió devolver los fondos gubernamentales transferidos con este objetivo, considerando que eran insuficientes para la satisfacción de los requerimientos del gobierno central. El tema generó un intenso debate entre el presidente Correa y la municipalidad de Guayaquil. Finalmente, el gobierno municipal tuvo que asumir dichas competencias, aunque decidió mantener los subsidios al transporte público. ${ }^{46}$

Varios gobiernos seccionales atraviesan una situación difícil debido a la situación económica del país. El gobierno central adeuda varios millones de dólares correspondientes a la devolución de impuestos a varios municipios. Para agravar la situación, una de las primeras medidas para afrontar la crisis económica fue la disminución de las asignaciones presupuestarias a los gobiernos autónomos descentralizados para el año 2016. La reducción, según se ha anunciado, equivale a un porcentaje de entre el 8\% y 10\% del total de los valores recibidos durante el año 2015 (El Comercio, 2015m).

Finalmente, es necesario destacar que a pesar de que AP perdió fuerza en los cargos de elección popular (alcaldes municipales y prefectos), el gobierno central cuenta con

46 En la ciudad de Quito se decidió incrementar la tarifa de los taxis y mantener la de los buses. El municipio capacitó a varios funcionarios para efectuar el control del tránsito en la ciudad, y generó un sistema de compensaciones monetarias entregadas a las cooperativas de transporte por el cumplimiento de determinados estándares de calidad de servicio. 
participación en niveles de gobiernos seccionales, a través de direcciones provinciales de varios ministerios, y principalmente de gobernadores designados directamente. Sin embargo, estos funcionarios no ejercen tareas de administración ni gobierno, y tampoco tienen participación directa en el presupuesto asignado a las administraciones seccionales.

\section{BALANCE DE CALIDAD DE LA DEMOCRACIA}

Si bien la desigualdad social se ha reducido en los últimos años, la calidad de la democracia en su dimensión institucional ha venido disminuyendo también. Usando diversas estrategias, el correísmo ha minado las instituciones que protegen las libertades civiles y políticas de los ciudadanos. A través del desprestigio a sus críticos, el Presidente ha socavado la confianza de los ciudadanos en la libertad al disenso. Y mediante leyes de difamación en el código penal y regulaciones administrativas de la ley de comunicaciones, el gobierno ha intimidado y censurado a los medios de comunicación.

Pero los ataques a la libertad de expresión se observan no solo en el control del gobierno sobre la prensa sino también en sus respuestas a la protesta social. Por ejemplo, se utilizó fuerza excesiva en contra de las protestas en el 2015, y se reportaron detenciones arbitrarias, donde los detenidos no tuvieron acceso a un abogado y desconocían los cargos que se les imputaba, además de recibir maltratos físicos durante la detención (Human Rights Watch, 2015). Y por si esto fuera poco, las nuevas prerrogativas de las Fuerzas Armadas concedidas por las enmiendas constitucionales para intervenir en las jornadas de protestas, abonan al ambiente de intolerancia al pluralismo.

La tolerancia política de los ecuatorianos también ha disminuido. Según LAPOP, entre el 2006 y el 2014, el apoyo a la libertad de expresión bajó de 54,6\% a 44,7\% y la aprobación de las protestas pacíficas bajó de 63,4\% a 58,1\% (Donoso, Montalvo, Orcés, y Zechmeister, 2014). En cuanto a las actitudes democráticas, en el 2014 Ecuador reportó el nivel de actitudes conducentes a la "democracia estable" más bajo de la región (19,5\%). Mientras que el nivel de actitudes conducentes a la "estabilidad autoritaria" llegó al 44,7\%, un incremento de 30 puntos desde el 2006, cuando se reportó que solo el 14,7\% exhibía estas actitudes. ${ }^{47}$

En contra de la tendencia de los años anteriores, la popularidad de Correa en el 2015 se ha desplomado, registrando en diciembre el punto más bajo de los nueve años de gobierno, a niveles similares que en la crisis económica del 2009 (ver Figura 7). Desde que inició su gobierno, Correa había contado con una popularidad sin precedentes, sosteniendo un promedio de $62 \%$ de popularidad en todos los años de su gobierno. Por encima del Presidente más popular de la historia del Ecuador, Jaime Roldós, que tuvo en promedio 56\% de aprobación (El Comercio, 2014). Y se reeligió en el 2013 con más

47 De acuerdo con la clasificación de actitudes democráticas de LAPOP, la "estabilidad autoritaria" es una mezcla de baja tolerancia política con alto apoyo al sistema (Donoso et al., 2014). 
Figura 7. Aprobación presidencial

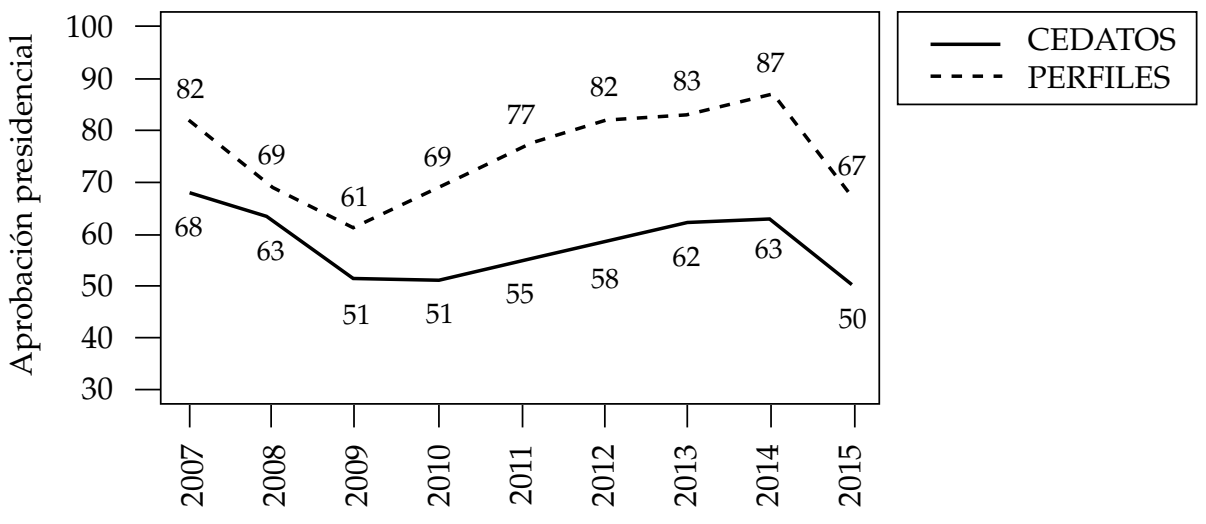

Años

Fuente: CEDATOS y Perfiles de Opinión.

del $57 \%$ de los votos, gracias a los réditos políticos de varios años de intensa inversión social en educación, salud e infraestructura. Sin embargo, en el 2015, la protesta social y los bajos niveles de aprobación serían evidencia del crecimiento del descontento social con su gobierno.

Gran parte del debilitamiento de la popularidad del Presidente responde al malestar social con su estilo de gobierno y a la situación económica actual. Esto afecta el debate sobre el balance de los nueve años de la "Revolución Ciudadana", donde por un lado se recuperó el rol del Estado, se luchó contra la concentración de la riqueza y se mejoró la calidad de vida de la ciudadanía, mientras que por otro lado, se socavaron las instituciones democráticas. Se avanzó en lo social, favoreciendo la inclusión de sectores sociales desaventajados, pero se retrocedió muchísimo en lo político (de la Torre y Ortiz Lemos, 2015). Y ahora que el boom de los commodities llegó a su fin, las contradicciones del proyecto político de Correa se hacen más evidentes.

\section{CONCLUSIONES}

En el 2015 confluyeron una serie de problemas que han generado incertidumbre política en torno al futuro de la "Revolución Ciudadana" de Correa. La insatisfacción ciudadana se hizo sentir a través de masivas jornadas de protesta en contra de múltiples reformas legislativas del oficialismo. El gobierno respondió con llamados a la confrontación y la defensa de la "Revolución Ciudadana", y con la intervención policial, que en repetidas veces terminó en detenciones arbitrarias. Asimismo, el presidente Correa intensificó los ataques a la libertad de expresión. Y el oficialismo en la Asamblea Nacional aprobó enmiendas constitucionales que preocupan por su potencial para la restricción de derechos fundamentales de los ciudadanos. 
La crisis económica a raíz del desplome de los precios del petróleo ha forzado al gobierno a recortar la inversión pública y a recurrir a más endeudamiento, generándose dudas sobre la capacidad del gobierno de cumplir con sus obligaciones fiscales. Además, la difícil situación económica ha puesto en evidencia la contradicciones del modelo económico que, aunque ha reducido significativamente la pobreza y desigualdad, ha mantenido la dependencia a las exportaciones de materias primas, en particular a las industrias relacionadas al petróleo. En medio del debate inconcluso sobre si el país ha aprovechado adecuadamente el consumado boom de los commodities para sentar las bases de un desarrollo autónomo e inclusivo, el declive de la aprobación presidencial, uno de los mayores recursos del gobierno después de la inversión social, alimenta la sensación de descontento social con el gobierno de Correa.

Como consecuencia de todas estas complicaciones, la decisión de Correa de no participar en los comicios del 2017 abre una serie de escenarios políticos donde se contempla por primera vez en nueve años la posibilidad de un gobierno sin Correa, o incluso, del fin de la "Revolución Ciudadana". Aunque la salida de Correa le permita evitar los costos políticos del debilitamiento de su partido y de la crisis económica, le queda pendiente encontrar un sucesor a su liderazgo fuerte, una tarea difícil para un proyecto político personalista como el suyo. A la fecha, no hay presidenciable concreto ni de parte del oficialismo ni de la oposición. El desenlace de esta incertidumbre política, dependerá de cómo el gobierno en el 2016 maneje la crisis económica y el debate sobre el legado de la "Revolución Ciudadana", así como de la capacidad de los grupos de oposición de superar su fragmentación interna.

\section{REFERENCIAS}

Basabe-Serrano, Santiago y Martínez, Julián. 2014. "Ecuador: Cada vez menos democracia, cada vez más autoritarismo... con elecciones". Revista de Ciencia Política 34 (1): 145-170.

Basabe-Serrano, Santiago y Llanos Escobar, Santiago. 2014. “La Corte Suprema del Ecuador en el período democrático (1979-2013): entre la inestabilidad institucional y la influencia partidista". América Latina Hoy 67: 15-63.

Basabe-Serrano, Santiago; Pachano, Simón y Mejía Acosta, Andrés. 2010. “La democracia inconclusa: derechos fundamentales, instituciones políticas y rendimientos gubernamentales en Ecuador (19792008)". Revista de Ciencia Política 30 (1): 65-85.

Basabe-Serrano, Santiago; Polga-Hecimovich, John y Mejía Acosta, Andrés. 2013. Ministers and the Goldilocks Effect: Cabinet Volatility and Presidential Stakes in Ecuador, 1979-2012. Paper presentado en la Asociación Latinoamericana de Ciencia Política (ALACIP), Bogotá, Colombia.

Borja, Raúl. (ed.). 2014. Balance crítico del gobierno de Rafael Correa. Quito: Universidad Central del Ecuador. Castañeda, Jorge, G. 2006. "Latin America's left turn”. Foreign Affairs 85 (3): 28-43.

CNE. (2015). "CNE aprueba inscripción del partido político Fuerza Ecuador". Consejo Nacional Electoral (9 de octubre).

Dabrowski, Marek. 2015. "The impact of the oil-price shock on net oil exporters". Bruegel (24 noviembre). En: http://bruegel.org/2015/11/the-impact-of-the-oil-price-shock-on-net-oil-exporters/.

De la Torre, Carlos y Ortiz Lemos, Andrés. 2015. "Populist polarization and the slow death of democracy in Ecuador". Democratization: 1-21.

Diario El Telégrafo. 2015a. "La derecha buscará capitalizar los resultados de las protestas porque tiene los recursos y la capacidad mediática" (17 de agosto). En: http://www.eltelegrafo.com.ec/noticias/ 
politica/2/la-derecha-buscara-capitalizar-los-resultados-de-las-protestas-porque-tiene-los-recursosy-la-capacidad-mediatica.

.2015b. "Se juntaron todos los posibles y no han logrado nada" (14 de agosto). [En línea.] http:/ / www. eltelegrafo.com.ec/noticias/politica/1/correa-se-juntaron-todos-los-posibles-y-no-han-logrado-nada.

2015c. "Fernando Bustamante se compromete a acatar sanción de PAIS" (23 de diciembre). En: http://www.eltelegrafo.com.ec/noticias/politica/2/asambleista-fernando-bustamante-secompromete-a-acatar-sancion-de-pais.

Diario El Comercio. 2014. “Roldós y Correa, los mejor calificados en 40 años” (31 de diciembre). En: http:// www.elcomercio.com/actualidad/roldos-correa-mejor-calificados-historia.html.

. 2015a. "Una tensa espera de los 21 de El Arbolito y sus familiares" (17 de diciembre). En: http:// www.elcomercio.com/actualidad/quito-21deelarbolito-familiares-boletas-libertad.html.

.2015b. "Manuela Picq de va de Ecuador porque considera que no existen garantías" (21 de agosto). En: http://www.elcomercio.com/video/manuela-picq-ecuador-brasil.html.

2015c. "Con plantón se insistió en la liberación de acusado de transportar material explosivo" (28 de diciembre). En: http://www.elcomercio.com/actualidad/planton-liberacion-acusadotransportista-guayaquil.html.

2015d. "Relatora especial de la ONU se pronunció sobre los enfrentamientos entre policías y manifestantes en el Ecuador" (24 de agosto). En: http://www.elcomercio.com/actualidad/ relatoraespecial-onu-manifestaciones-ecuador-paronacional.html.

. 2015e. "El FMI envió 10 recomendaciones a Ecuador" (23 de octubre). En: http:/ / www.elcomercio. $\mathrm{com} /$ actualidad/fmi-recomendaciones-ecuador-economia.html.

. 2015f. "De regreso al FMI" (sin fecha). En: http://www.elcomercio.com/opinion/regreso-fmiecuador-opinion-economia.html.

2015g. "Ecuador cumplirá pago de \$ 650 millones en bonos 2015 de deuda externa" (11 de diciembre). En: http://www.eluniverso.com/noticias/2015/12/11/nota/5291727/ ecuador-cumplira-pago-650-millones-bonos-2015-deuda-externa.

. 2015h. "Coca, endeudada y desesperada luego del fin del 'boom' petrolero" (22 de noviembre) En: http://www.elcomercio.com/actualidad/coca-endeudada-desesperada-luego-boom.html.

. 2015i. "La OPEP mantiene su techo oficial de producción en 30 millones de barriles diarios" (5 de junio). En: http:/ /www.elcomercio.com/actualidad/opep-produccion-petroleo-barriles.html.

.2015j. "Administrador de Crudo Ecuador recibió supuestas amenazas" (19 de febrero). En: http:// www.elcomercio.com/actualidad/crudo-ecuador-amenazas-fundamedios-redes.html.

.2015k. "Presidente Correa acepta la renuncia de Ramiro González" (14 de abril). En: http:/ / www. elcomercio.com/actualidad/rafaelcorrea-renuncia-ramirogonzalez-ministerioindustrias-avanza.html.

. 2015l. "El régimen conserva el apoyo del sector de los transportistas" (6 de noviembre). En: http://www.elcomercio.com/actualidad/ecuador-regimen-conserva-apoyo-transportistas.html.

. 2015m. "Alcaldías pequeñas sufrirán más el ajuste del 2016" (23 de noviembre) En: http:/ / www. elcomercio.com/actualidad/alcaldiaspequenas-sufriran-ajuste-proforma2016-ecuador.html.

. 2016a. "Fernando Bustamante presentó su solicitud de desafiliación de Alianza País" (28 de enero). En http://www.elcomercio.com/actualidad/alcaldiaspequenas-sufriran-ajuste-proforma2016ecuador.html.

.2016b. "Frente de activistas sociales propone a José Delgado como precandidato a la presidencia" (11 de enero). En: http://www.elcomercio.com/actualidad/activistas-proponen-josedelgadocandidato-presidencia.html.

.2016c. (19 de marzo). "Pesántez se presentó como precandidato a la presidencia con una caravana y un concierto" [En línea].

. 2016d. "Enmiendas, 2 nuevas demandas irán a la Corte Constitucional" (7 de enero). En: http:// www.elcomercio.com/actualidad/enmiendas-demandas-corte-inconstitucionalidad-ecuador.html.

. 2016e. "Jubilados plantearon una nueva demanda de inconstitucionalidad de las enmiendas" (21 de enero). En: http://www.elcomercio.com/actualidad/jubilados-demanda-inconstitucionalidadenmiendas-ecuador.html. 
2016f. "Alianza País bloquea a Fernando Bustamante" (22 de enero de 2016). En: http:/ /www. elcomercio.com/actualidad/alianzapais-bloqueo-fernandobustamante-ecuador-politica.html.

Diario El Universo. 2015a. "Rafael Correa dice que IESS tiene superávit por lo que 'no tiene sentido' darle el 40\% para pensiones" (26 de marzo). En: http://www.eluniverso.com/noticias/2015/03/26/ nota/4704431/correa-dice-que-iess-tiene-superavit-que-no-tiene-sentido-darle-40.

2015b. "Secretaría Nacional de Inteligencia niega contratos con empresa que ofrece servicios de espionaje" (10 de julio). En: http://www.eluniverso.com/noticias/2015/07/10/nota/5011474/ secretaria-inteligencia-niega-contratos-empresa-que-ofrece.

2015c. "Asambleístas intentaron ingresar a las supuestas instalaciones de la SENAIN" (15 de julio). En: http://www.eluniverso.com/noticias/2015/07/15/nota/5020570/ asambleistas-intentaron-ingresar-supuestas-instalaciones-senain.

2015d. "Nueva previsión de crecimiento de Ecuador es 0,4\% para 2015, dice el Banco Central" (30 de septiembre). En: http://www.eluniverso.com/noticias/2015/09/30/nota/5157293/ nueva-prevision-crecimiento-ecuador-es-04-2015-dice-banco-central.

. 2015e. "Expresidente Rodrigo Borja apoya por firmas para ID, pese a su retiro" (13 de diciembre). En: http://www.eluniverso.com/noticias/2015/12/13/nota/5293914/borja-apoya-firmas-pese-su-retiro.

. 2015f. "Ramiro González cree en la unidad de criterios para tratar crisis económica" (17 de diciembre). En: http://www.eluniverso.com/noticias/2015/12/17/nota/5303130/ ramiro-gonzalez-cree-unidad-criterios-tratar-crisis-economica.

2015g. "Petroecuador arranca proceso de despidos de personal por bajos precios del crudo" (22 de octubre). En: http://www.eluniverso.com/noticias/2015/10/05/nota/5168282/ petroecuador-arranca-proceso-despidos-personal-bajos-precios-crudo.

2015h. "Periodista Roberto Aguilar rindió confesión judicial" (17 de noviembre). En: http:/ /www. eluniverso.com/noticias/2015/11/17/nota/5246505/roberto-aguilar-rindio-confesion-judicial.

.2015i. “Corte Constitucional ya tiene sus tres nuevos jueces" (8 de octubre). En: http:/ / www.eluniverso. com/noticias/2015/10/08/nota/5173037/ corte-constitucional-ya-tiene-sus-tres-nuevos-jueces.

2015j. "Maresa ofrece a ministros recontratar a despedidos" (19 de diciembre). En: http:/ /www. eluniverso.com/noticias/2015/12/19/nota/5305155/maresa-ofrece-ministro-recontratar-despedidos.

Donoso, J. C., Montalvo, D., Orcés, D. M., \& Zechmeister, E. J. 2014. Cultura política de la democracia en Ecuador y en las Américas, 2014: Gobernabilidad democrática a través de 10 años del Barómetro de las Americas: Vanderbilt University.

Freidenberg, Flavia. 2015. "En Tierra De Caciques! Liderazgos Populistas Y Democracia En Ecuador". Opera 16: 99-130.

Gamso, Jonas. 2016. "A Case of Diversified Dependency: Macrostructural Change and Policy Alternatives in Ecuador". Latin American Perspectives 43 (1): 109-123.

Human Rights Watch. 2015. Ecuador Recuperado de New York: https:/ / www.hrw.org/americas/ecuador. Kitzberger, Philip. 2016. "Counterhegemony in the Media under Rafael Correa's Citizens' Revolution". Latin American Perspectives 43 (1): 53-70.

Martínez-Gallardo, Cecilia. 2005. “Designing Cabinets: Presidents, Politics and Policymaking in Latin America". Unpublished PhD Dissertation. New York: Columbia University.

Martínez-Gallardo, Cecilia. 2014. "Designing Cabinets: Presidential Politics and Ministerial Instability". Journal of Politics in Latin America 6 (2): 3-38.

Navia, Patricio. 2015. "The end of the left turn in Latin America?". Buenos Aires Herald (11 de marzo).

Ospina Peralta, Pablo. 2015. “¿Por qué protestan en Ecuador? Rafael Correa y el fracasado aumento del impuesto a las herencias". Nueva Sociedad 258 (Julio-Agosto): 121-130.

Pachano, Simón. 2010. "Ecuador: El nuevo sistema polítco en funcionamiento". Revista de Ciencia Política 30 (2): 297-317.

Polga Hecimovich, John. 2013. “Ecuador: estabilidad institucional y la consolidación de poder de Rafael Correa". Revista de Ciencia Política 33 (1): 135-160.

Polga-Hecimovich, John. 2014. “ ¿ Hacia una superación del «cleavage» regional? La nacionalización de los partidos políticos ecuatorianos desde el retorno a la democracia". América Latina Hoy 67: 91-118. 
Sanchez Urribarri, Raúl, A. 2011. "Courts between democracy and hybrid authoritarianism: evidence from the Venezuelan Supreme Court". Law \& Social Inquiry 36 (4): 854-884.

Weller, Nicholas y McCubbins, Kenneth. 2014. "Raining on the Parade: Some Cautions Regarding the Global Database of Events, Language and Tone Dataset". Political Violence @ a Glance Blog (20 de febrero). En: http://politicalviolenceataglance.org/2014/02/20/ raining-on-the-parade-some-cautions-regarding-the-global-database-of-events-language-and-tone-dataset/.

Sofía Vera Rojas es candidata a PhD en Ciencia Política con especialización en política comparada, por la Universidad de Pittsburgh. E-mail: sbv2@pitt.edu.

Santiago Llanos-Escobar es candidato a maestro en Ciencia Política por la Facultad Latinoamericana de Ciencias Sociales, FLACSO-Ecuador. E-mail: santiagollanosescobar@gmail.com. 


\section{ANEXO 1 \\ ENMIENDAS CONSTITUCIONALES}

\begin{tabular}{ccc}
\hline $\mathrm{N}^{\mathrm{o}} \quad$ Enmiendas & Contenido & $\begin{array}{c}\text { Reforma específica a la } \\
\text { Constitución }\end{array}$ \\
\hline
\end{tabular}

1 Enmienda sobre consulta Establecimiento de limites a la popular en GADS

2 Reelección indefinida de 2 autoridades de elección popular.

3 Reelección indefinida Presidente de la República

4 Reducción de la edad mínima para ser Presidente de la República

5 Establecimiento de tareas complementarias a las Fuerzas Armadas

6 Modificación de las competencias de la Contraloría General del Estado

7 Modificación de las competencias de la Contraloría General del Estado

8 Modificación del Régimen Territorial de la Defensoría del Pueblo

9 Modificación del régimen legal de los obreros del sector público posibilidad de convocar a consulta popular en los gobiernos autónomos descentralizados (GAD). Se limita los asuntos materia de la consulta al régimen de competencias de cada GAD.

Se elimina todo límite para la reelección de autoridades de elección popular.

En específico, se elimina todo límite para la reelección del Presidente de la República.

La edad mínima para postular a la Presidencia de la República se disminuye de 35 a 30 años.

Las Fuerzas Armadas reciben la facultad de colaborar con la seguridad interna del Estado. De esta forma, podrán realizar tareas anteriormente exclusivas de la Policía Nacional

Disminución de las atribuciones de la Contraloría General del Estado, específicamente la posibilidad de evaluar con base en los objetivos de las entidades públicas.

Disminución de atribuciones de la Contraloría, específicamente al no poder revisar las gestiones.

Sujeción de la Defensoría del Pueblo a la organización territorial de la Función Judicial, de acuerdo a las disposiciones del Consejo de la Judicatura.

Eliminación de los artículos que indican que los obreros del sector público (trabajo físico) y sus relaciones laborales se regulan por el Código del Trabajo -sector privado-
Modificaciones a los incisos tercero y cuarto del artículo 104 de la Constitución.

Modificaciones a los artículos 114 de la Constitución.

Modificación al artículo 144 de la Constitución.

Modificación al artículo 142 de la Constitución.

Sustitución del segundo inciso del artículo 158 de la Constitución

Reforma al artículo 211 de la Constitución

Reforma al numeral 2 del artículo 212 de la Constitución.

Reformas al artículo 214 de la Constitución de la República.

Eliminación del tercer inciso del artículo 229 de la Constitución 
$\mathrm{N}^{\mathrm{o}} \quad$ Enmiendas

Contenido

10 Modificación del régimen legal de los obreros del sector público

11 Cambio del régimen de competencias de los GADs y del gobierno central.

12 Establecimiento de requerimientos para que el gobierno central pueda ocuparse de la infraestructura de educación y salud

13 Modificación al régimen de seguridad social de las fuerzas del orden

14 Modificación al régimen de seguridad social general

15 Establecimiento de la comunicación como servicio público

16 Enmienda sobre el tiempo de conformación de regiones autónomas
Inclusión de los obreros del sector público al régimen laboral de los servidores públicos en general

Se incrementan las atribuciones del gobierno central en el ámbito de la implementación de infraestructura pública.

Se prevé que el gobierno central podrá encargarse de la consevación de la infraestructura en los sectores de salud y educación previo autorización del ente rector de la política pública.

Se establece una garantía expresa sobre el pago de las pensiones jubilares de los miembros de la Policía Nacional y de las Fuerzas Armadas.

Dentro de las normas que especifican el manejo de los fondos del régimen de seguridad social, se elimina la palabra provisional y se establece la palabra previsional.

Se establece dentro del texto constitucional que la comunicación es un servicio público, y las formas en las que puede prestarse.

Se elimina el tiempo límite para la conformación de las regiones autónomas, previsto anteriormente en ocho años.
Reforma específica a la Constitución

Reforma al artículo 326 del texto constitucional. Inclusión de una disposición transitoria.

Modificación del artículo 261, numeral 6 de la Constitución.

Sustitución del numeral 7 del artículo 264 del texto constitucional

Modificación del texto del artículo 370 de la Constitución

Modificación del artículo 372 del texto constitucional.

Incremento de un nuevo primer inciso en el artículo 384 de la Constitución.

Reforma al numeral 9 de la disposición transitoria primera de la Constitución. 
